Portland State University

PDXScholar

\title{
A longitudinal study of the disfluencies of four and six year old children
}

Mary B. Cox

Portland State University

Follow this and additional works at: https://pdxscholar.library.pdx.edu/open_access_etds

Part of the Speech Pathology and Audiology Commons Let us know how access to this document benefits you.

\section{Recommended Citation}

Cox, Mary B., "A longitudinal study of the disfluencies of four and six year old children" (1989). Dissertations and Theses. Paper 3865.

https://doi.org/10.15760/etd.5749

This Thesis is brought to you for free and open access. It has been accepted for inclusion in Dissertations and Theses by an authorized administrator of PDXScholar. Please contact us if we can make this document more accessible: pdxscholar@pdx.edu. 
AN ABSTRACT OF THE THESIS OF Mary B. Cox for the Master of Science in Speech Communication: Speech Pathology presented April 20, 1989

Title: A Longitudinal study of the Disfluencies of Four and Six Year old Children.

APPROVED BY MEMBERS OF THE THESIS COMMITTEE:
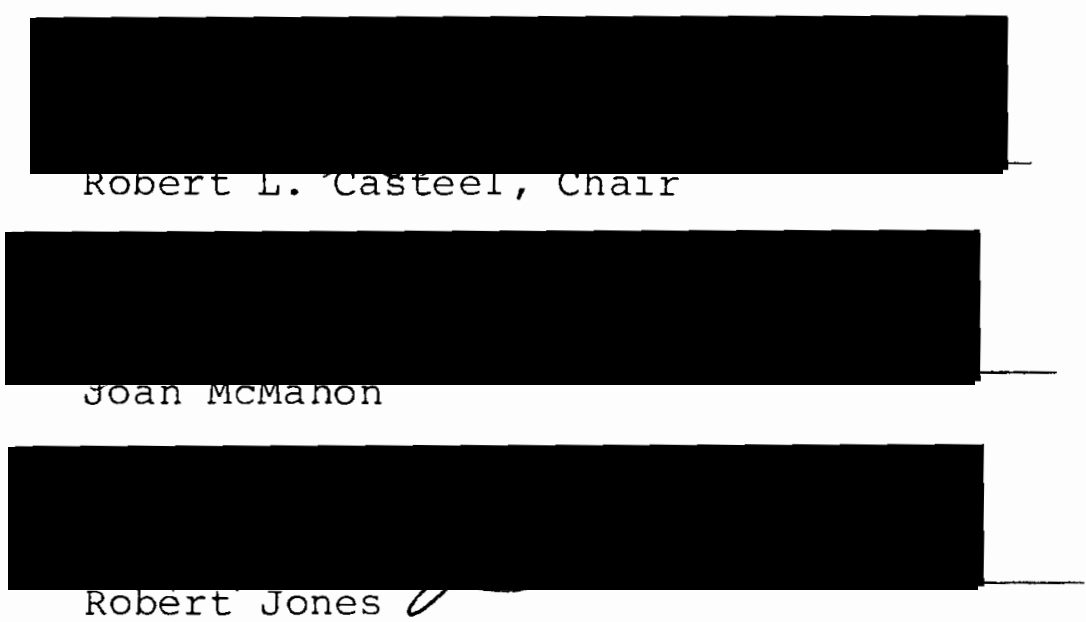

Investigations into the speech of normal children have indicated that disfluencies are common. It is important for the Speech Language Pathologist to have knowledge of normal disfluencies for differential diagnosis, parent counseling, and in order to plan strategies for intervention.

The purpose of this study was to compare the frequency of disfluencies in 4 year old and 6 year old normal male children to the frequency of disfluencies when they were 3 years old and 5 years old respectively. 
One year later, eighteen of the twenty normal male children used in a previous study were reevaluated in this study. At the time of the current study, nine children were 4 and nine children were 6 years old. All subjects met specific criterion. Transcripts were made of speech samples and seven disfluency types were identified following the same procedures as in the previous study.

All statistically significant changes in specific disfluency types for individual subjects were decreases in mean production when compared to subjects of the same age group according to the Dixon Massey Test of Statistical outliers. Two 4 year old children and three 6 year old children each significantly decreased one specific disfluency type. No statistically significant change was found in mean total disfluencies per 100 words when each child was compared to others in his age group.

Negligible correlation was found between initial ranking and current rank order according to the spearman Rank Order Coefficient. Expectancy Tables were created from the data to assist in predicting future disfluency when baseline information is known for specific disfluency types and total mean disfluencies per 100 words.

The findings are consistent with previous studies indicating that interjections, word repetitions, and revision-incomplete phrases are prevalent disfluency types and that disrhythmic phonations are among the least common disfluency types in normal 4 and 6 year old 
children. The findings also support earlier studies indicating that a prevalence of disrhythmic phonations may signify abnormal disfluency. 
A LONGITUDINAL STUDY OF THE DISFLUENCIES

OF FOUR AND SIX YEAR OLD CHILDREN

by

MARY B. COX

A thesis submitted in partial fulfillment of the requirements for the degree of

\author{
MASTER OF SCIENCE \\ in \\ SPEECH COMMUNICATION: SPEECH PATHOLOGY
}

Portland State University 
TO THE OFFICE OF GRADUATE STUDIES:

The members of the committee approve the thesis of Mary B. Cox presented April 20, 1989.

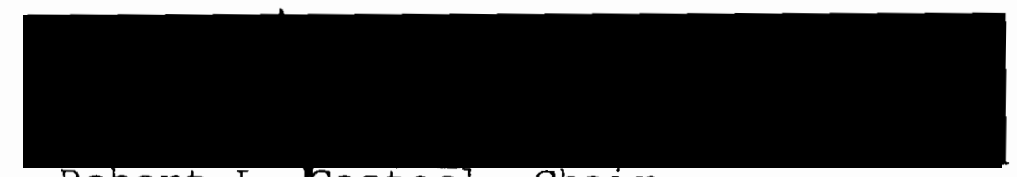

Robert L. Casteel, Chair

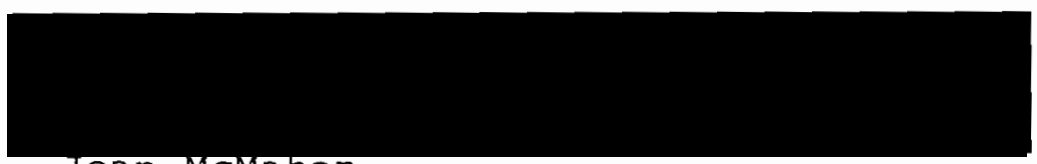

Joan McMahon

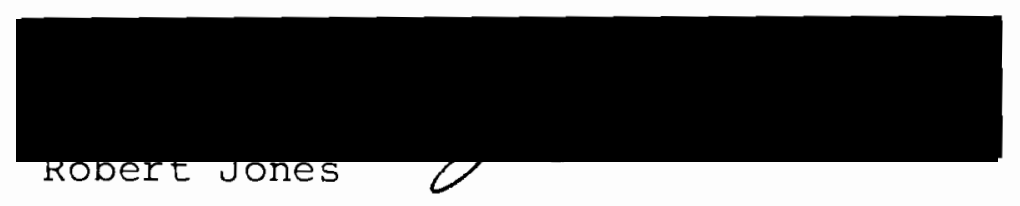

APPROVED:

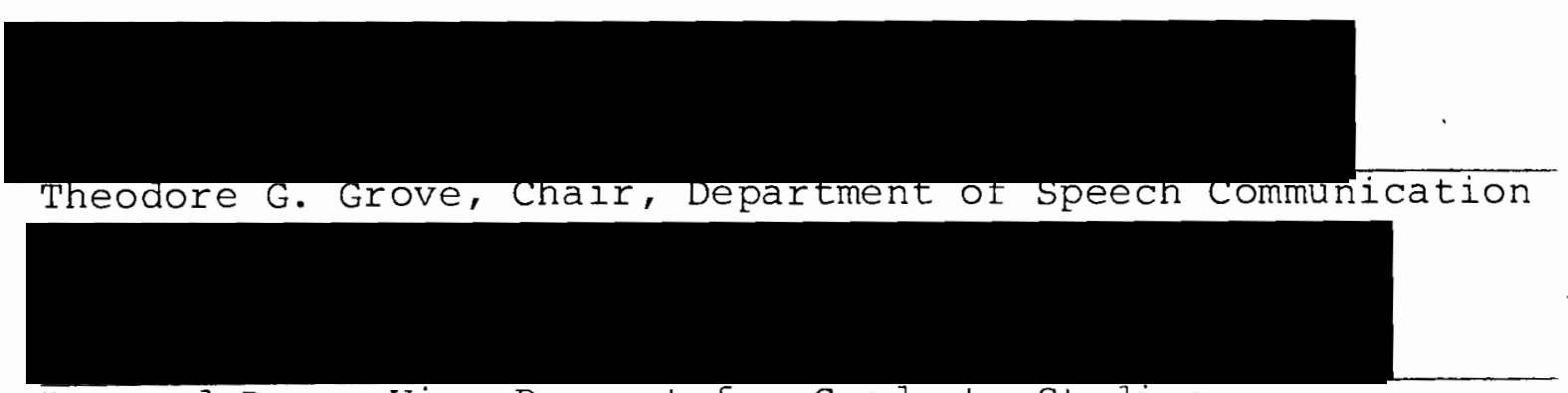

Bernard Ross, Vice Provost for Graduate Studies 


\section{ACKNOWLEDGEMENTS}

I would like to express my gratitude to Robert I. Casteel, my thesis adviser, for generously sharing his time, his insights, and his support. His excellent guidance and encouragement have been primary factors in the completion of this project.

I am also grateful to both Joan McMahon and Robert Jones, for their editing and participation on my committee.

I would like to thank those students who participated in videotaping and in the reliability testing. I especially appreciate the hours susan Crowell spent videotaping my subjects and providing much needed encouragement.

My deepest gratitude goes to my family. I am thankful to my children, Olivia and Jason, who have been extremely flexible and have put up with a mother who hasn't been there even when she's been there. I am extremely grateful for the emotional support, encouragement and loving child care which my parents, Helen and John Boles, have provided. 
TABLE OF CONTENTS

PAGE

ACKNOWLEDGEMENTS $\ldots \ldots \ldots \ldots \ldots \ldots \ldots \ldots \ldots \ldots \ldots \ldots \ldots \ldots \ldots \ldots$

LIST OF TABLES......................... vi

LIST OF FIGURES........................ vii

CHAPTER

I INTRODUCTION $\ldots \ldots \ldots \ldots \ldots \ldots \ldots \ldots \ldots \ldots \ldots \ldots$

Statement of Purpose............. 3

Definition of Terms............. 4

I I REVIEW OF ThE Literature............. 7

Normal Disfluencies.............. 7

Three Year old Children
Four Year old Children
Five Year old Children
Six Year Old Children
Longitudinal Data

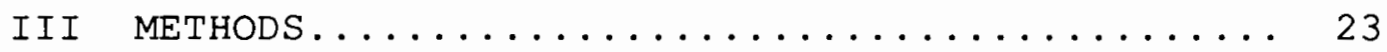

Subjects................... 23

Subject Eligibility Procedures

Speech Sample procedures........... 25

Scoring Procedures.............. 25

Reliability................ 26

Data Analysis.................. 27 


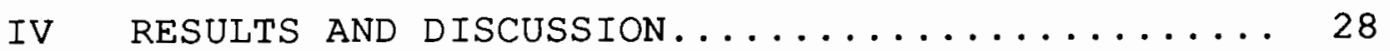

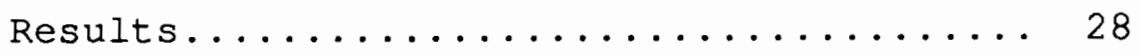

Questions

Discussion.........................41

Individual Changes

Expectancy Tables

Comparisons

V SUMMARY AND IMPLICATIONS............... 51

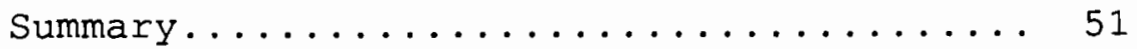

Implications...................... 54

Clinical

Research

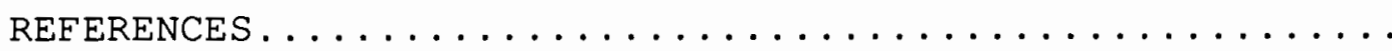

APPENDICES

A CONSENT FORM....................... 60

B LETTER OF INTRODUCTION ............... 62

C EOLLOW UP LETTER.................... 64

D $\quad$ LIST OF STIMULI.................... 66

E RULES FOR CALCULATING 300 WORD SAMPLES ....... 68

F RULES FOR IDENTIFYING DISFLUENCIES ......... 71

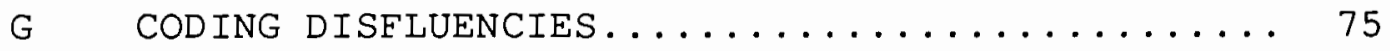

H INSTRUCTIONS FOR SELECTION OF CONTENT

TRANSCRIPTS FOR RELIABILITY TESTING...... 77

I INSTRUCTIONS TO RELIABILITY JUDGES .......... 80 


\section{LIST OE TABLES}

TABLE

PAGE

I Means per 100 Words for Disfluency Types and

Total of All Disfluencies at Each Age...... 29

I Dixon Massey Outilers Analysis of the Summary

of Differencies Between 1987 and 1988 Means

for Disfluency Types and Totals for Each

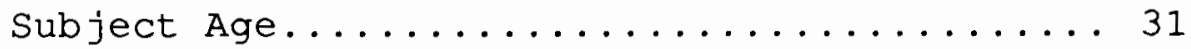

II Expectancy Tables for Disfluency Types...... 34

IV Expectancy Tables: Total of All Disfluencies. 40

V Summary of the Spearman Rank Order Coefficient

Rank Order of the Total Mean Disfluencies

per 100 Words for 1987 and 1988 Collapsed

Groups............................ 42 


\section{LIST OF FIGURES}

FIGURE

PAGE

1 A review of the literature (Davis [1939]

through Oxtoby [1943]): Comparisons of mean

disfluency types per 100 words at four age

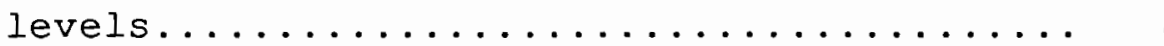

2 A review of the literature (Egland [1955]

through wexler [1982]): Comparisons of mean

disfluency types per 100 words at four age

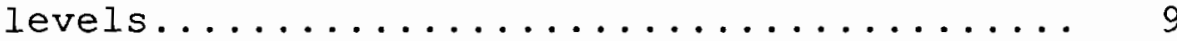

3 A review of the literature (Wexler [continued] through DeJoy \& Gregory [1985]): Comparisons of mean disfluency types per 100 words at four

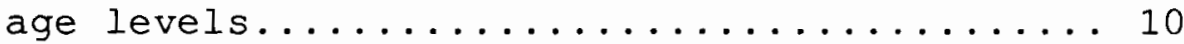

4 A review of the literature (Arnold-Cockburn [1987] through Semler [1987]): Comparisons of mean disfluency types per 100 words at four

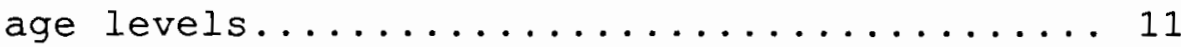


CHAPTER I

\section{INTRODUCTION}

Investigations into the speech of normal children have indicated that disfluencies are common (Davis 1939; Egland 1955; Branscom, Hughes, and Oxtoby 1955; Johnson, Brown, Curtis, Edney, and Klaster 1959; Yairi \& Clifton 1972; and Floyd and Perkins 1974). Starkweather (1985) acknowledges that disfluencies are present in normal speech when he notes that fluency cannot be defined totally as the absense of stuttering. Rather, he notes, fluency exists on a continuum; from speech requiring little energy and time, to speech requiring considerable energy and time. The speech-Language Pathologist is often called upon to determine where, along this continuum, fluency requires so much energy that it is no longer normal and may require intervention.

A differential diagnosis of stuttering is important in order to plan strategies for intervention and implement parent counseling. Early diagnosis can lead to successful management of preschool stuttering children (Shine 1980). Once in treatment, knowledge of normal disfluencies also may determine treatment goals. These should not surpass the 
fluency of that exhibited by normal children.

studies to date have investigated the characteristics of stuttering children (Bloodstein 1960; Bloodstein and Grossman 1981; and Yairi 1983). Others have compared disfluencies of normal children to those exhibited by children identified as stutterers (Johnson, et al. 1959; Floyd and Perkins 1974; Winkler \& Ramin 1986; and Yairi and Lewis 1984). Normal disfluencies in children have also been examined at discrete age levels (Davis 1939; Branscom, Hughes, and Oxtoby 1955; Kools and Berryman 1971; Silverman 1972; Yairi and Clifton 1972; Haynes and Hood 1977; Wexler 1982; DeJoy and Gregory 1985).

However, there are few longitudinal studies of disfluencies of normal children (Yairi 1981; Yairi 1982). Investigations of this type have inherent advantages not present in other studies. Definitions and types of disfluencies examined can be consistent across studies and variability in methods can be diminshed. These benefits add validity to comparisons across studies and credibility to interpretations.

This study will contribute longitudinal data to the literature on normal disfluencies in children. New data will be gathered about the disfluencies of the same children evaluated in a 1987 study by Christiansen. At that time, 10 of the male children were 3 and 10 were 5 years old. Information from that investigation indicated that 
the younger children did not produce a greater overall frequency of disfluencies than the 5 year old children; tense pauses were presented equally between the groups; neither group produced a great frequency of disfluency types associated with incipient stuttering: part word repetitions, disrhythmic phonations and tense pauses; the 5 year olds exhibited a significantly greater frequency of interjections than the 3 year old children; the 3 year olds produced a greater frequency of part word repetitions, word repetitions, and phrase repetitions than the older children, but not at a chosen significance level. Data from the present study will be compared longitudinally with that of this earlier study.

STATEMENT OF PURPOSE

The purpose of this study was to compare the frequency of disfluencies in 4 year old and 6 year old normal male children to the frequency of disfluencies when they were 3 years old and 5 years old respectively. The following specific disfluency types will be examined: part-word repetitions, word repetitions, phrase repetitions, disrhythmic phonations, interjections, revision-incomplete phrases, and tense pauses.

The present investigation will answer the following questions:

Does the total frequency of occurrence of each 
disfluency type change significantly over time for each subject?

Does the total of all disfluency types combined differ significantly over time for each subject?

How does the rank order of individual children compare over time?

\section{DEFINITION OF TERMS}

To maintain continuity with the 1987 Christiansen study the same definitions were incorporated into the present investigation and additional ones presented to clarify terminology found in other studies.

Clustering: more than one disfluency on consecutive words or the same word or both (Silverman 1969 as reported by Wexler and Mysak 1982).

Disfluency: involuntary whole and part-word repetitions or prolongations, silent or audible, resulting in an interruption of the forward flow of speech (Van Riper 1971; Wingate 1964).

Disrhythmic phonation: a disturbance or distortion of the normal rhythm or flow of speech by within-word phonation. Included are sound prolongations and broken words (Williams, Silverman and Kools 1968).

Frequency: defined by Riley (1972) as the number of disfluencies per 100 words of speech. 
Grammatical pause.: A grammatical juncture characterized by a silent pause. (DeJoy and Gregory 1985).

Incipient stutterer: An individual beginning to exhibit disfluent behavior outside normal limits (Adams 1977). Intervention may be required in that spontaneous recovery is not anticipated.

Interjections: Extraneous sounds such as "uh, "er," and "hmm," and extraneous words such as "well," which are not part of the phrase or sentence (Johnson $1961)$.

Intrusive schwa: The intrusion of the neutral schwa vowel instead of the intended vowel. Example: "duh-duh-daddy" (Van Riper 1971).

Nonfluency: Interruption in the forward flow of speech; synonymous with disfluency (Christiansen 1987 ). Normal disfluency: Disfluent speech behavior exhibited by most speakers not requiring intervention or concern (Christiansen 1987).

Parallel talk: _As defined by Van Riper, is an individual commenting on what a child is doing, perceiving, or feeling, and also allowing moments of silence, while playing with the child, to encourage the child to verbalize (Emerick and Hatten 1979).

Oscillation: Number of repetitions per disfluency instance (Wexler and Mysak 1982). Referred to as unit repetitions by Branscom et al. (1955). 
which is less than the entire word. Includes sound repetitions, and syllable repetitions. Examples: "t-toy"; "ma-ma-man" (Christiansen 1987) Phrase repetition: Unintentional repetition of two or more words without changing the content. An example of two units of phrase repetition would be, "See the, see the, see the car" (Johnson et al. 1959).

Repetition instance: The occurrence of a part-word, whole word, or phrase repetition, regardless of the number of times the part-word, whole word, or phrase is reiterated. Example: "See, see, see the $d$-dog," is two instances of repetitions (Johnson 1961).

Repetition unit: The number of times a part-word, word, or phrase is repeated, but does not include the most complete form. Example: "I see, I see" is both one instance and one unit of repetition; "da-da-da-daddy" is one instance of repetition but three units of repetitions (Christiansen 1987).

Revision-incomplete phrase: A content, grammatical or semantic modifications of an incomplete phrase (Johnson 196I). Example: "We is - are going." Tense pauses: Barely audible heavy breathing or muscular tightening between part-words, words, and nonwords (Williams, Silverman, and Kools 1968). Ungrammatical pauses: Silent pauses not related to grammatical junctures (DeJoy and Gregory 1985). 


\section{CHAPTER II}

\section{REVIEW OF THE LITERATURE}

\section{NORMAL DISFLUENCIES}

Data concerning disfluencies in the speech of preschool children is varied and sparse. A review of studies into normal disfluencies will serve as a basis for further investigations.

Three Year old Chilaren

Focus of early research was on the frequency of repetitions in the speech of preschool children. In 1939, Davis studied the speech of 62 normal children aged from 24 to 60 months (Davis 1939). Phrase repetitions were found to be the most prevalent and word repetitions occurred more frequently than part-word repetitions. Although the older children duplicated the same general pattern as that of the two year olds, the frequency was lower.

These findings were not supported in the analysis of the dysfluencies of nineteen 3 year old children in the 1942 Branscom investigation (Branscom, Oxtoby, and Hughes 1955). Word repetitions occured the most frequently while phrase repetitions outnumbered part-word repetitions. Support for the Davis (1939) study was later found in a 1943 examination of the disfluencies of thirteen 3 year old 


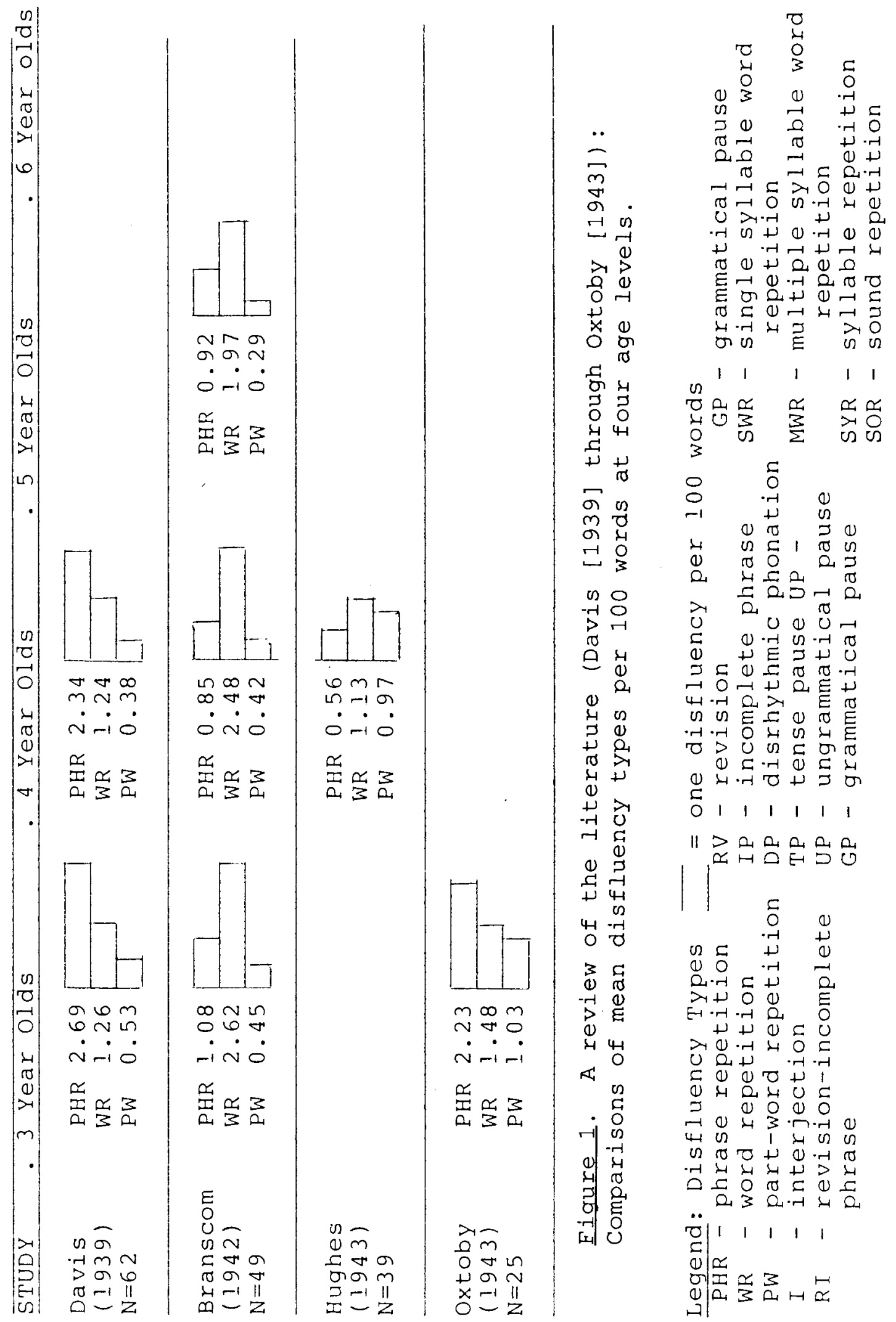




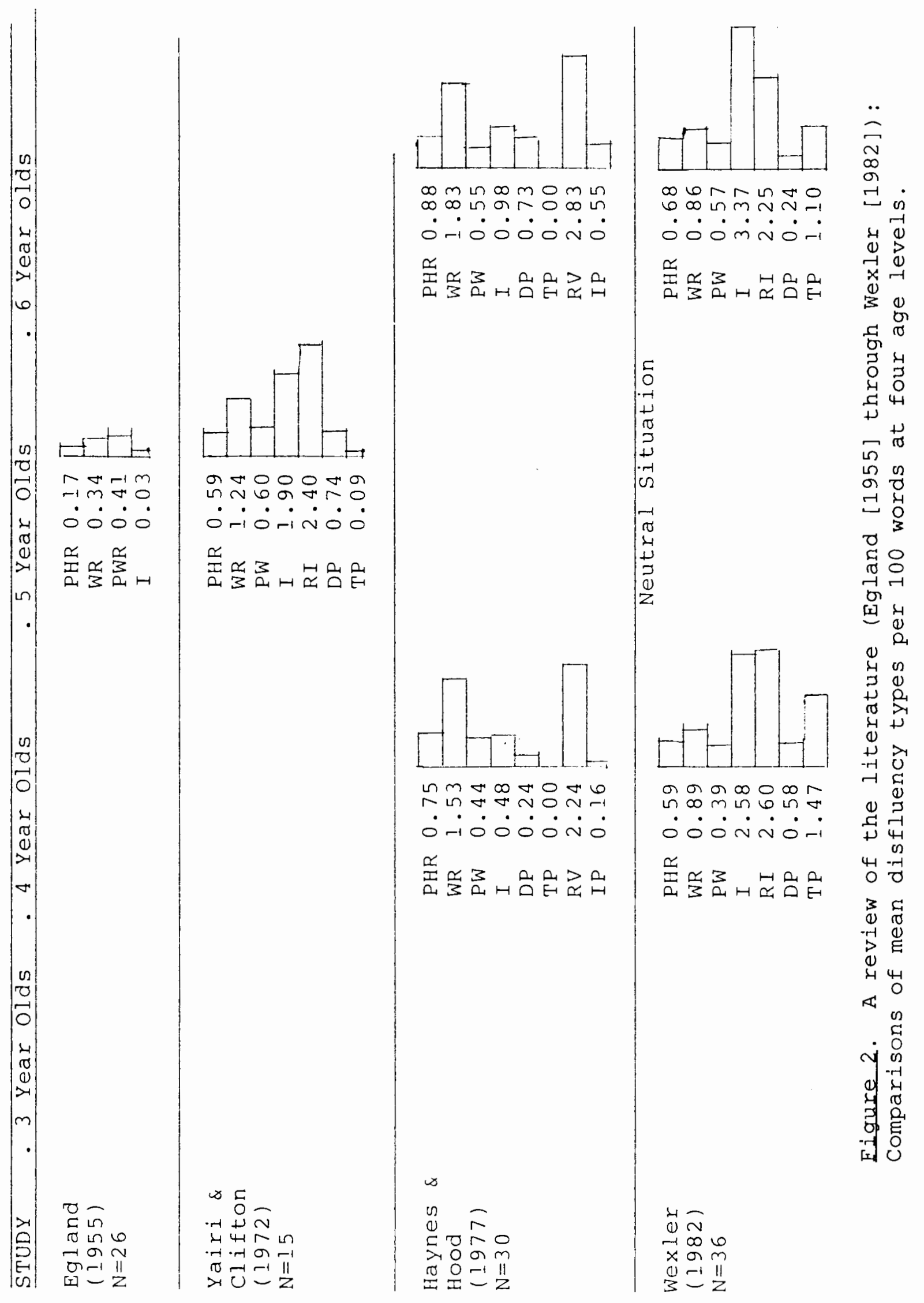




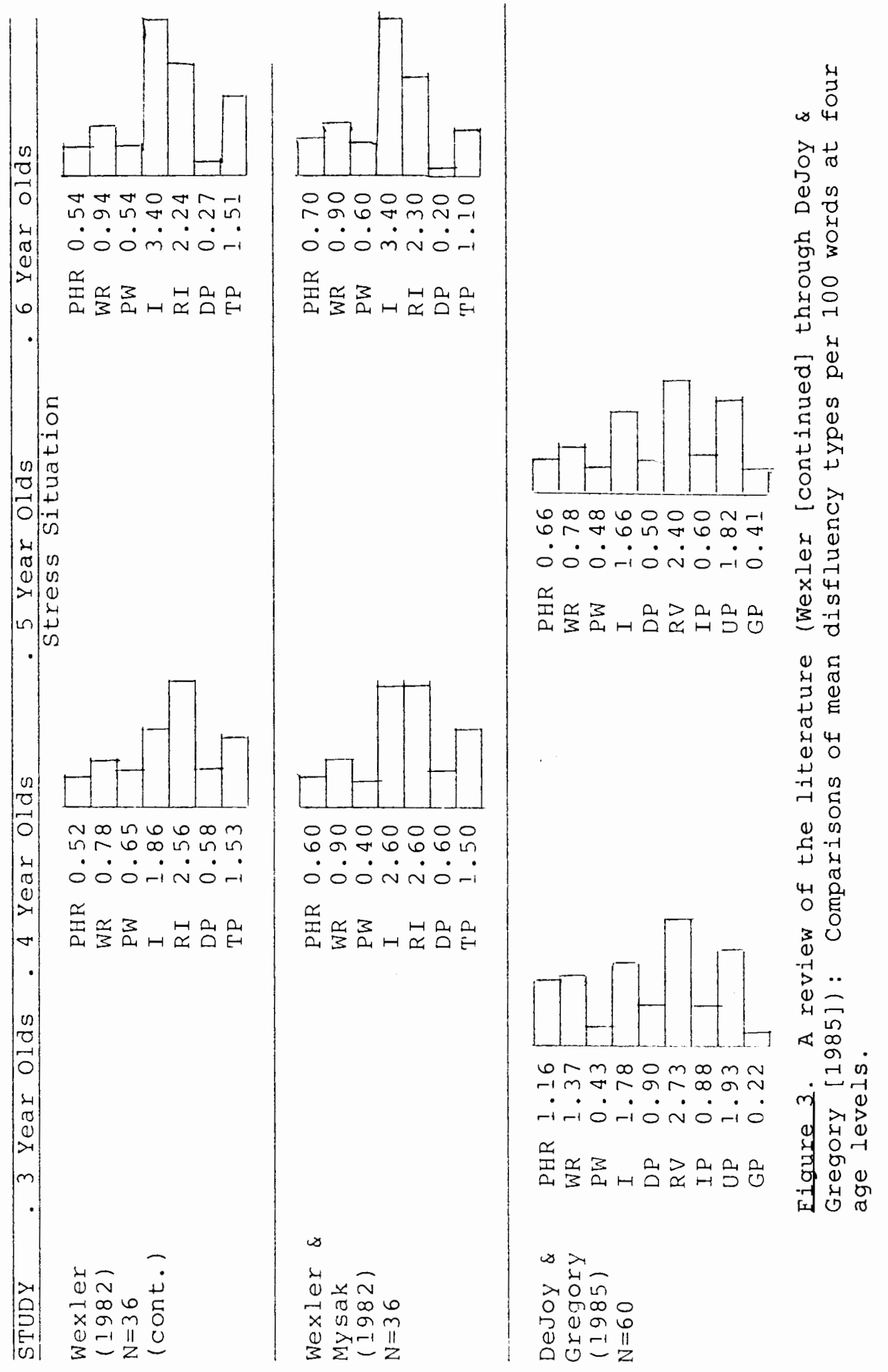




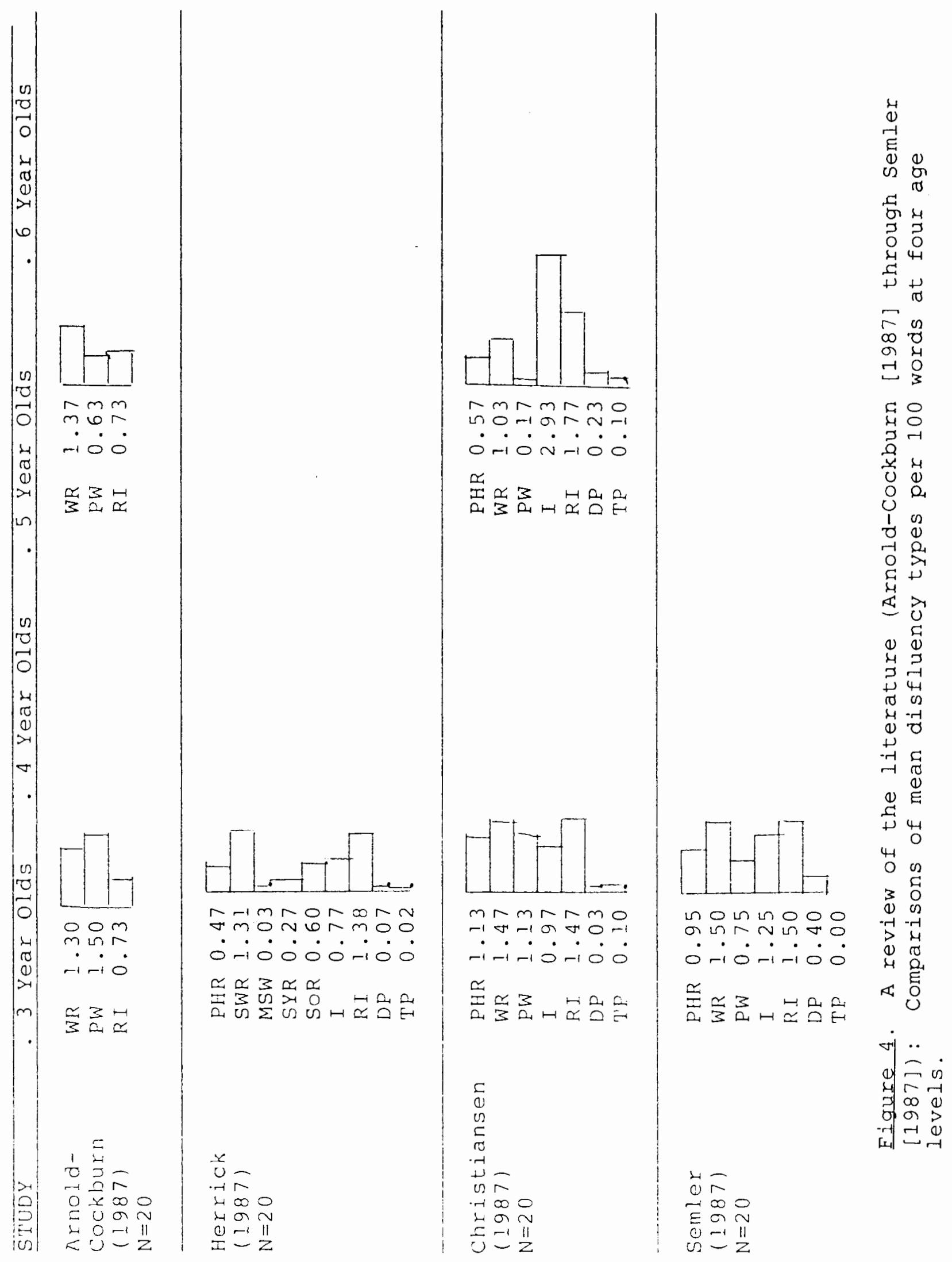


children by Oxtoby (Branscom et al. 1955). Phrase repetitions were produced with the greatest frequency, followed by word repetitions, then part-word repetitions. DeJoy and Gregory (1985) divided the disfluencies of thirty 3 l/2 year old males and thirty 5 year old males into 9 categories. Revisions were produced the most frequently, followed in order of decreasing frequency: ungrammatical pauses, interjections, word repetitions, phrase repetitions, disrhythmic phonations, incomplete phrases, part-word repetitions, and grammatical pauses. Analysis of repetitions support Branscom's 1942 (Branscom 1955) investigation and indicate that $31 / 2$ year olds produced significantly more phrase repetitions, word repetitions, part-word repetitions, incomplete phrases and disrhythmic phonations than the 5 year olds. Ungrammatical pauses, revisions and interjections were found to occur with no significant difference between the two age groups. However, significantly fewer grammatical pauses occurred in the $31 / 2$ year old group.

It is interesting to note that all studies to this point agree that the least frequently produced repetition is the part-word repetition. This was not supported in a study by Arnold-Cockburn (1987) of twenty females aged 30 to 36 months old and 54 to 60 months old. The younger children demonstrated a greater number of part-word repetitions, followed by word repetitions, then revision-incomplete phrases. Significantly more part-word 
repetitions were produced by the younger children than the older ones.

The same year, Herrick studied the disfluencies of twenty male children ranging in ages from 30 to 36 months (Herrick 1987). The frequencies of word repetitions and phrase repetitions were found to be significantly greater than part-word repetitions. Revision-incomplete phrases were found to be the most frequent, followed by: whole word repetitions, interjections, sound repetitions, phrase repetitions, syllable repetitions, dischythmic phonations, multisyllable word repetitions, and tense pauses.

In a study by christiansen (1987) of ten 3 year old males and ten 5 year old males, disfluencies of the younger children occurred in the following decending order: revision-incomplete phrases, word repetitions, phrase repetitions, interjections, part-word repetitions, tense pauses, disrhythmic phonations. These results confirm the findings of the DeJoy and Gregory (1985) and the Branscom's 1942 (Branscom et al. 1955) investigations indicating that word repetitions were more numerous than phrase repetitions, and phrase repetitions were more numerous than part-word repetitions. All the repetitions were produced at a greater frequency in the younger children than the older ones. In addition, the Christiansen (1987) study supported the results of the DeJoy and Gregory (1985) investigation in that revision-incomplete phrases occurred 
with the greatest frequency in the speech of 3 year olds. other analysis indicates that the younger children in the Christiansen (1987) investigation did not produce a higher overall frequency of disfluencies than the 5 year old children. In fact, interjections were produced in a significantly greater frequency by the older children.

An additional 1987 study by semler of 10 boys and 10 girls between the ages of 33 to 39 months support the Christiansen (1987) investigation indicating that whole word repetitions and phrase repetitions were produced with greater frequency than part-word repetitions. The descending frequency is as follows: whole word repetitions, revision-incomplete phrase, interjections, phrase repetitions, part-word repetitions, and dysrhythmic phonations.

In reviewing the literature, it appears that word repetitions, phrases repetitions, interjections and revision- incomplete phrases are frequently produced by normal 3 year old children.

Four Year old Children

In the Davis (1939) study, four year old males and females produced more phrase repetitions than word repetitions and part-word repetitions were the least numerous. Although the order of prevalence remained the same as it had at the 2 and 3 year age levels, both the number of disfluencies within each category and the total of 
all disfluencies were less than those of the three year olds in the study.

The total number and frequency of each disfluency type were also less than those of the 3 year old children for the ten 4 year old male and female children in Branscom's 1942 (Branscom et al. 1955) study. The pattern remained the same across age levels within this study; word repetitions were the most numerous followed by phrase repetitions, then part word repetitions. Branscom et al. (1955) reported that, in 1943, Hughes studied 29 four year old female and male children and substantiated the Branscom study indicating that word repetitions were the most numerous. However, part-word repetitions outnumbered phrase repetitions. These results differ from those of 2 year old children, obtained in the same study. Although word repetitions were the most frequent in this younger age group, phrase repetitions were more frequent than part-word repetitions.

The speech of thirty 4 year old males was evaluated in a 1977 study by Haynes and Hood (Haynes and Hood, 1977 ). Frequency of each disfluency type, in order from most frequent to least frequent, were as follows: revisions, word repetitions, phrase repetitions, interjections, part-word repetitions, disrhythmic phonation, and incomplete phrases. No tense pauses were produced by these subjects. Again, word repetitions were the most frequent of the repetitions. The pattern presented in the 1942 Branscom (Branscom et al. 
1955) was duplicated in that phrase repetitions were present at a greater level of frequency than part-word repetitions. Interjections and revision-incomplete phrases were found to be the most frequent disfluencies among thirty-six 4 year old male children in a 1982 study by wexler and Mysak (1982). Produced with decreasing frequency were: tense pauses, word repetitions, then disrhythmic phonations, phrase repetitions, and part-word repetitions. As in the 1942 Branscom (Branscom et al. 1955) and the Haynes and Hood studies (1977), word repetitions occurred with greater frequency than phrase repetitions, and phrase repetitions occurred with greater frequency than part-word repetitions.

This pattern was again duplicated during neutral stress situations in another study of thirty-six 4 year old male children by wexler (1982). Revision-incomplete phrases were the most frequently produced, followed by interjections, tense pauses, word repetitions, phrase repetitions, disrhythmic phonations, and, finally, part-word repetitions. However, during stress situations in the same study, the pattern changed. Revision-incomplete phrases, interjections, tense pauses, and word repetitions followed the same pattern. The remainder changed order of frequency: part-word repetitions, disrhythmic phonations, and phrase repetitions. These results substantiate those of Hughes in 1943 (Branscom 1955), perhaps indicating that situational variables can account for discrepancies between studies. In 
both situations, the overall frequency of disfluencies was less for the 4 year old group than the 2 year old group.

Thus far, it appears that the overall frequency of disfluency decreases with age and that revision or revision-incomplete phrase and interjections are the most numerous disfluency types demonstrated by 4 year olds. Of the repetition types, word repetitions appear to be produced the most frequently.

Five Year old Children

Data from the 1942 Branscom (Branscom et al. 1955) study indicated word repetitions were the most frequent, followed by phrase repetitions, then part-word repetitions by 5 year old children. Although this pattern of disfluencies was maintained across age groups, the overall rate of disfluency decreased when compared to 3 year old children in the study.

This pattern of repetitions was not supported in a later study by Egland (1955) of twenty-six 5 year old male and female children. Part-word repetitions were found to be the most frequent, followed by word repetitions, then phrase repetitions and, finally, interjections.

Yairi and Clifton (1972) divided the disfluencies produced by fifteen 5 year old male and female children into 7 types. Presented in order of decreasing frequency, they include: revision-incomplete phrase, interjection, word repetition, disrhythmic phonation, part-word repetition, 
phrase repetition and tense pauses. As in the 1942 Branscom (Branscom et al. 1955) study, word repetitions were the most prevalent of the repetitions. However, part-word repetitions outnumbered phrase repetitions.

In a 1985 investigation of the disfluencies of sixty 5 year old males by DeJoy and Gregory (DeJoy and Gregory 1985) categorized disfluencies into 9 types, presented in decreasing frequency: revisions, ungrammatical pauses, interjections, word repetitions, phrase repetitions, incomplete phrases, disrhythmic phonations, part-word repetitions, and grammatical pauses. Word repetitions were found to occur with greater frequency than phrase repetitions Following the pattern of the 1942 Branscom investigation (Branscom et al. 1955), phrase repetitions occurred with greater frequency than part-word repetitions. In analyzing the speech of ten 5 year old females, Arnold-Cockburn (1987) found word repetitions to be produced the most frequently followed by revision-incomplete phrases and then part-word repetitions. This data agreed with the results of most studies (Branscom et al. 1942, Yairi and Clifton 1972, and DeJoy and Gregory 1985) indicating that word repetitions were the most prevalent of the three types of repetitions in the 5 year old age group. The Arnold-Cockburn (1987) study also confirmed Branscom's 1942 (Branscom, et al. I955) and DeJoy and Gregory's (1985) findings indicating that part-word repetitions were produced 
with the least frequency. In comparing the two age groups Arnold-Cockburn found that the 3 year old children produced significantly more part-word repetitions than the 5 year old children. However, there was no significant difference in the total number of disfluencies between the age groups. This contrasts with the 1942 Branscom (Branscom et al. 1955 ) and the DeJoy and Gregory (1985) studies in which the overall number of repetitions decreased from the 3 year group to the 5 year group, and the Davis (1939) investigation indicating a decrease in total repetitions from 2 years to 4 years.

Christiansen (1987) found that ten 5 year old boys produced the following 7 types of disfluencies from greatest to least frequency: interjections, revision-incomplete phrases, word repetitions, phrase repetitions, disrhythmic phonations, part-word repetitions, and tense pauses. As in the Branscom (Branscom et al. 1955), and DeJoy and Gregory (1985) studies, word repetitions occurred with the greatest frequency followed by phrase repetions. Part-word repetitions were produced the least frequently of the repetitions. Supporting the Arnold-Cockburn investigation (1987), Christiansen found no significant difference between the overall frquency of disfluencies at the 3 and 5 year age levels. Although there was no statistical difference, the 5 year old children produced a greater overall frequency of disfluencies than the younger children. The older children 
exhibited a greater frequency of interjections while phrase repetitions, word repetitions, and part-word repetitions decreased.

It appears that interjections, revision-incomplete phrases, and word repetitions are consistently the most numerous disfluencies among 5 year olds and that total disfluency production does not necessarily decrease.

Six Year old Children

In examining the speech of 6 year old children, Haynes and Hood (1977) found revisions to be produced the most frequently, followed by: word repetitions, interjections, phrase repetitions, dischythmic phonations, incomplete phrases, and part-word repetitions. Tense pauses were not produced. No significant differences in the total frequency of disfluencies were found between 4 year old and 6 year old subjects studied. Both age groups produced revisions, word repetitions, phrase repetitions, and interjections the most frequently. In comparing the repetitions it was found that the same pattern was present in both groups; word repetitions were the most numerous, followed by phrase repetitions and part-word repetitions.

Interjections and repetitions were exhibited with the greatest frequency in the speech of 6 year old children in the 1982 wexler and Mysak study of twelve 6 year old males. Revision-incomplete phrases, tense pauses, and word repetitions then occurred in that order. This is the same 
pattern of repetitions as that of 4 year olds in the same study: word repetitions, phrase repetitions, then part-word repetitions. This order is also exhibited by the 6 year olds in the Haynes and Hood (1977) study.

Wexler (1982) examined the disfluencies 6 year old male children in neutral stress situations and stress situtations. There was no change in the overall pattern of Erequency of occurrence between the situations at the 6 year age level. Interjections occurred with the greatest Erequency, followed by revision-incomplete phrase, then tense pauses, word repetitions, phrase repetitions, part-word repetitions, and disrhythmic phonations. This contrasts to the 4 year age level at which revision-incomplete phrases occured with the greatest frequency, followed by interjections, then tense pauses in both stress and neutral situtations. The frequency of all repetitions decreased with age in the neutral situations. Phrase repetitions, word repetitions, and part- word repetitions decreased with age in all situations, with the exception of word repetitions in stress situations. They occurred with decreased frequency at the 4 year level. However, the Erequency increased during stress in the 6 year old children.

Consistent with earlier ages, 6 year olds tend to produce interjections, revisions, or revision-incomplete phrases, and word repetitions the most frequently. Total 
disfluency production appears to remain constant.

In looking at all studies it appears that interjections, revisions, or revision-incomplete phrases, and word repetitions are the most frequently produced. Total disfluency production appears to decrease in some studies with age. However, recent data seems to suggest that while frequency of individual disfluency types vary with age, total disfluency production does not change significantly with age.

Longitudinal Data

In the only previous longitudinal study, Yairi (1982) examined disfluencies in the speech of two to three year old children every four months for a year. He found variability within the speech of individual children. Large fluctuations were found in disfluencies produced between each period, causing Yairi (1982) to conclude that the age studied was one of great variability in disfluency production. 


\section{CHAPTER III}

\section{METHODS}

\section{SUBJECTS}

One year later, eighteen of the twenty normal male children used in the Christiansen (1987) study were reevaluated in the present study. At the time of the current study, nine children ranged in ages for 45 to 53 months $(x=49.5)$, and nine children ranged in ages from 70 to 74 months $(x=72)$. During the previous study the subjects met the following criteria:

1. English as the primary language in the home.

2. Speech intelligibility of at least 75 percent as calculated for a 100 word speech sample taken out of context ( 3 year olds).

3. A mean length of response of a least 2.5 words ( 3 year olds).

4. No history of middle ear infections or allergies.

5. No history of a hearing loss as reported by the parent or caregiver.

6. No history of developmental delay, retardation, neurological, or physical impairment as reported by the parent.

7. No cold at the time of the recording session. 
8. Had not been considered to have intervention or counseling for fluency problems.

9. Able to attend to a low stress task for at least 15 minutes.

10. Children between 57 to 63 months passed a hearing screening test for the better ear at $25 \mathrm{dBHL}$ for the pure tone frequencies of $500,1000,2000$, and $4000 \mathrm{~Hz}$.

11. Criteria for hearing adequacy for the 33 to 39 month old children were no history of middle ear infections or a cold at the time of the recording session.

In addition to meeting the original criteria, consent forms requesting information concerning a change in status of any of the criteria was signed by the subjects' parent or guardian prior to videotaping (Appendix A). No changes were reported. Additionally, all children were required to pass a pure tone hearing screening test for the better ear at $500,1000,2000$, and $4000 \mathrm{~Hz}$ SPL on the day of the videotaping

Subject Eligibility Procedures

A letter of introduction was mailed to each subject by the previous investigator (Appendix B). A follow-up letter (Appendix C) and phone call by this researcher confirmed subject availability and, at the same time, permission for the child to participate in the current study was requested. 
The consent form (Appendix A) also verified previous information and addressed changes in the subject's speech, family structure and environment. The parent was requested to return the completed consent form to the examiner prior to videotaping. A pure-tone screening test was also administered at $25 \mathrm{~dB}$ for the following frequencies: 500, 1000,2000 , and $4000 \mathrm{~Hz}$.

\section{SPEECH SAMPLE PROCEDURES}

The identical speech sample procedures were followed as in the 1987 study in order to maintain continuity. Approximately one year after the initial recording, a graduate student videotaped each child from behind a oneway mirror at the Portland State University Speech and Hearing Clinic with a Panasonic single camera recording system.

The speech sample was elicited during fifteen minutes of free play with toys and conversation with the investigator. Parallel talk and open-ended questions were utilized to stimulate verbalization while the child was presented with a box containing the same standardized set of toys that had been utilized in the previous study (see Appendix D for a List of Stimuli).

\section{SCORING PROCEDURES}

A 300 word sample for each subject was transcribed utilizing the same procedures as in the 1987 study (Appendix E for Instruction). Disfluencies were identified and 
classified according to the following categories: part-word repetitions, word repetitions, phrase repetitions, disrhythmic phonations, interjections, revision-incomplete phrases, and tense pauses (See Appendix F for Rules for Identifying Disfluencies, and Appendix $G$ for Coding symbols). The frequency of occurrence of each type of disfluency per 300 word sample was calculated for individual and group data.

\section{RELIABILITY}

A graduate student in the Portland State University speech and Hearing Sciences program utilized a random order table to select five videotaped language samples. Content transcripts omitting any type of disfluency were created using ten episodes from each of the five transcripts (see Appendix $H$ for instructions for selection of Content Transcripts.) A training session was held in which identification and coding of the deleted disfluencies of other videotaped language samples was undertaken by two different graduate students in the Portland State University Speech and Hearing Sciences program and the primary investigator (see Appendix I for Instructions to Reliability Judges). Videotapes of the five content transcripts were identified and coded, then the graduate students results were compared with each other and to those of the primary investigator to determine an interjudge reliability percentage of agreement. Agreement was $89 \%, 92 \%$ and $88 \%$ 
respectively. Samples were re-evaluated a week later and compared to previous results to determine an intrajudge percentage of agreement of $100 \%, 100 \%$, and $96 \%$.

\section{DATA ANALYSIS}

The means and standard deviations were calculated for the total disfluencies per 100 words and for each of the seven types of disfluencies for each subject and for each age group. Additionally, means and standard deviations of the percentage of disfluencies were re-calculated for the Christiansen study to include data from only those subjects participating in the present study.

Differences between initial data and that of a year later were analyzed using the Dixon Massey Test of Outliers (Dixon and Massey, 1957) and Expectancy Tables were created to answer questions regarding individual change. Significant variation in rank order of subjects was analyzed using the spearman Rank order Coefficient. 
CHAPTER IV

RESULTS AND DISCUSSION

\section{RESULTS}

The purpose of this study was to compare the amount and type of disfluencies of nine 4 year old and nine 6 year old normal male children to the amount and type of disfluencies demonstrated by them when they were 3 years old and 5 years old respectively. The total of all disfluencies combined and the following seven disfluency types were analyzed from spontaneous speech samples: part-word repetitions, word repetitions, phrase repetitions, interjections, revision-incomplete phrases, disrhythmic phonations, and tense pauses. Due to the small sample size for both age groups the results will be reported with some caution by the researcher in terms of generalizing the sample outcomes to the population. Results will be used to address the questions posed in Chapter I. For information purposes, means per 100 words from the current study and revised means from the Christiansen (1987) study are presented in Table I.

Questions

Does the total frequency of occurrence of each disfluency type change significantly over time for each subject? 
TABLE I

MEANS PER 100 WORDS FOR DISFLUENCY TYPES AND TOTAL OF ALL DISFLUENCIES AT EACH AGE

\begin{tabular}{|c|c|c|c|c|}
\hline & year olds & ${ }^{4}$ year olds & $\begin{array}{ll} & 5^{*} \\
\text { year olds }\end{array}$ & $\begin{array}{ll} & 6 \\
\text { year olds } \\
\end{array}$ \\
\hline $\begin{array}{l}\text { Part-word } \\
\text { Repetitions }\end{array}$ & .33 & .33 & .18 & .66 \\
\hline $\begin{array}{l}\text { Word } \\
\text { Repetitions }\end{array}$ & 1.52 & 1.22 & .89 & 1.04 \\
\hline $\begin{array}{l}\text { Phrase } \\
\text { Repetitions }\end{array}$ & 1.11 & .74 & .44 & .30 \\
\hline Interjections & .96 & 2.33 & 2.41 & 2.78 \\
\hline $\begin{array}{l}\text { Revision- } \\
\text { Incomplete } \\
\text { Phrase }\end{array}$ & 1.48 & 1.04 & 1.70 & 2.11 \\
\hline $\begin{array}{l}\text { Disrhythmic } \\
\text { Phonations }\end{array}$ & .04 & .00 & .26 & .00 \\
\hline $\begin{array}{l}\text { Tense } \\
\text { Pauses }\end{array}$ & .11 & .00 & .11 & .11 \\
\hline Total & 5.55 & 5.66 & 5.99 & 7.00 \\
\hline
\end{tabular}

* Revised means from the Christiansen (1987) study 
Means per 100 words of each disfluency type at each age level were determined for each child. The most recent means were subtracted from those of the previous year to determine the difference between mean productions for each disfluency for each child at each age. See Tables IIa and IIb for each subject's differences between the means for each disfluency type.

The Dixon-Massey Test of Outliers (1957) was used to analyze each difference. This test was chosen due to its applicability to determining variability in small sample sizes. At an alpha level of .05, significant decreases in five different disfluency types were produced by five subjects. Two 4 year old children were found to have made significant changes relative to the rest of that age group. One child decreased interjections at a mean difference of 2.34 and another decreased disrhythmic phonations by a mean of.33 per 100 words. Of the 6 year old age group, three children produced significantly fewer disfluencies. One subject decreased phrase repetitions by an average of 2.33 , another decreased interjections by an average of 4.33 , and the third decreased dischythmic phonations by an average of 1.0. Other variations in change were not statistically significant in relationship to other participants.

General age level, specific age level, mean production of disfluency and a combination of specific age and mean 


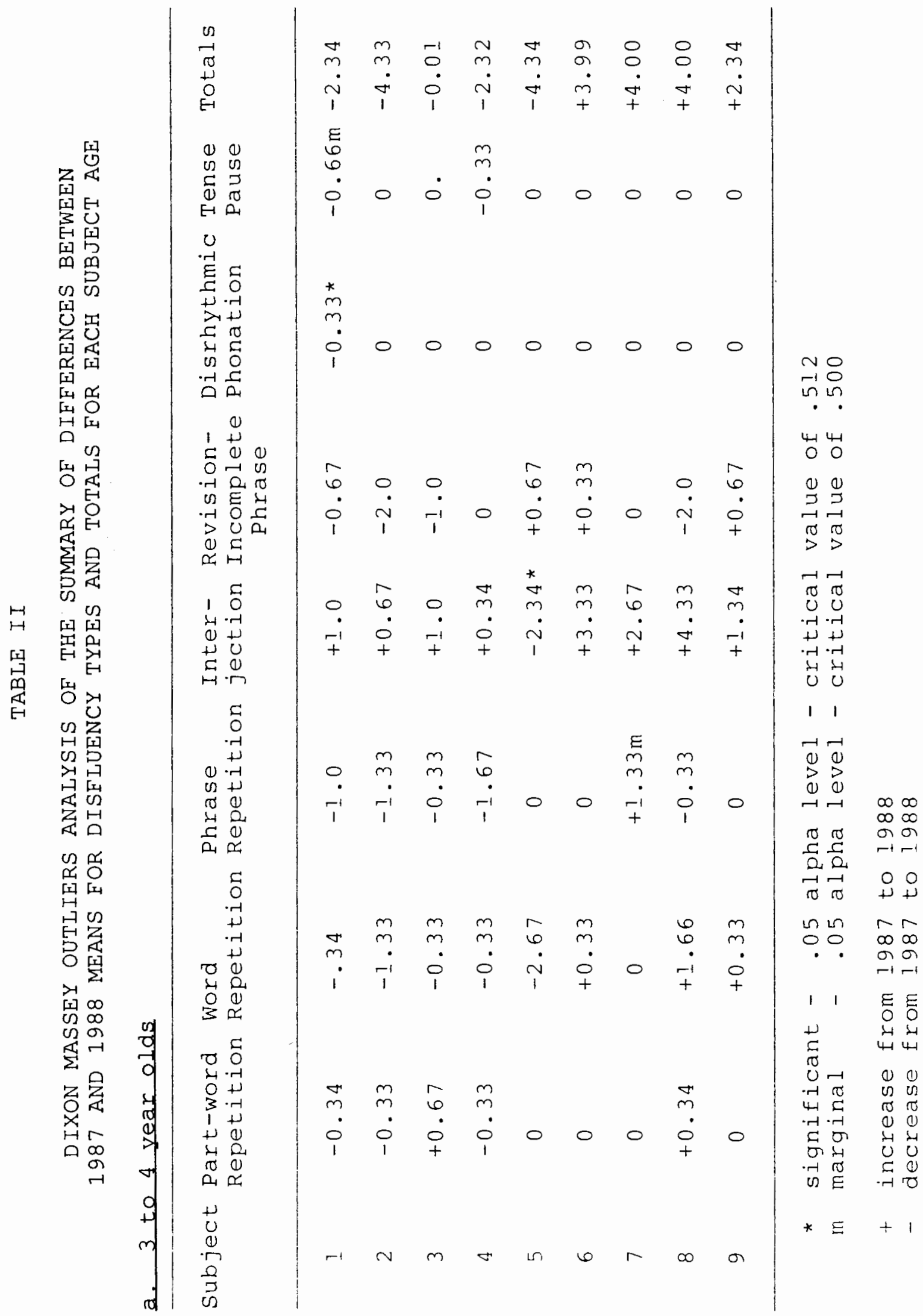




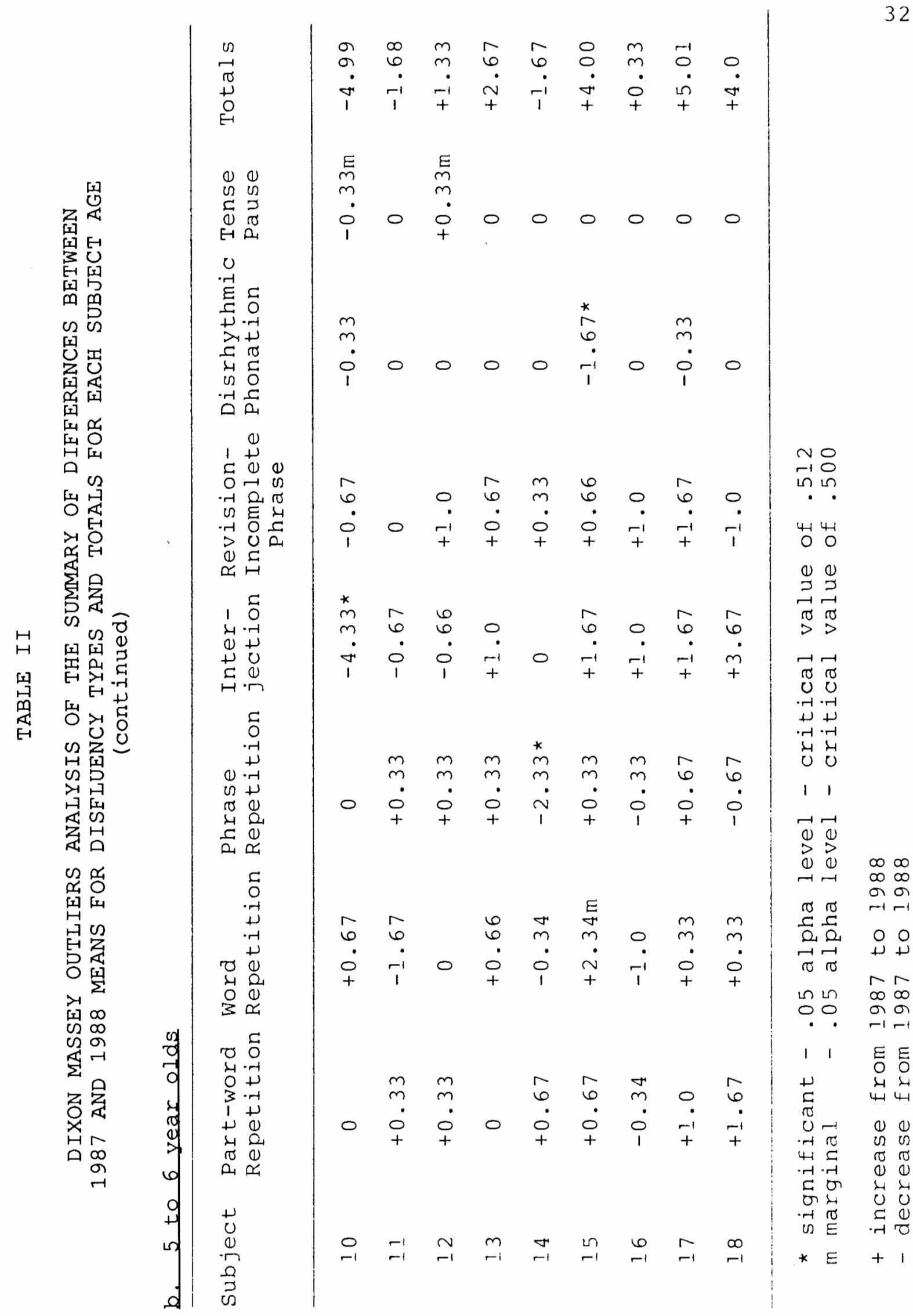


production of disfluency were related to the percentage of subjects who increased, decreased, or maintained the same mean level of production of disfluency. Resultant expectancy information for specific disfluencies can be seen in Tables IIIa through IIIg.

Does the total of all disfluency types combined differ significantly over time for each subject?

The mean total disfluencies per 100 words for each child was determined. The difference between the mean in 1987 and that of a year later were analyzed using The Dixon-Massey Test for Statistical Outliers (1957). An alpha level of .05 determined individual significance of change over time in relationship to other participants in the same age group. As can been seen in Tables IIa and IIb no significant variability was found in mean total disfluencies per 100 words.

Expectancy Tables were created by determining the percentage of subjects whose mean total of disfluencies per 100 words increased, decreased or remained constant over time. These changes were then analyzed according to the initial age level and the initial mean production of total disfluencies. See Table IV.

How does the rank order of individual children compare over time?

In order to use the Spearman Rank order Coefficient with the small n's in this study, the two groups were 
TABLE III

EXPECTANCY TABIES FOR DISFLUENCY TYPES

\section{a. Part Word Repetitions}

AGE: 3 year olds and 5 year elds combined

\begin{tabular}{lrrrr}
\hline \hline Mean per 100 words & More & Same & Fewer & Total \\
Not known & $44 \%$ & $33 \%$ & $33 \%$ & 18 \\
0 & $86 \%$ & $14 \%$ & $0 \%$ & 7 \\
.33 & $25 \%$ & $50 \%$ & $25 \%$ & 8 \\
.67 & $0 \%$ & $33 \%$ & $67 \%$ & $3 \%$ \\
\hline
\end{tabular}

AGE: 3 year olds

\begin{tabular}{lrrrr}
\hline Mean Der 100 words & More & Same & Fewer & Total \\
Not Known & $22 \%$ & $44 \%$ & $33 \%$ & 9 \\
0 & $50 \%$ & $50 \%$ & $0 \%$ & 2 \\
.33 & $20 \%$ & $40 \%$ & $40 \%$ & 5 \\
.67 & $0 \frac{\circ}{6}$ & $50 \%$ & $50 \%$ & 2 \\
\hline
\end{tabular}

AGE: 5 year olds

\begin{tabular}{lcccc}
\hline Mean per 100 words & Mere & Same & Fewer & Total \\
Not Known & $67 \%$ & $22 \%$ & $11 \%$ & 9 \\
0 & $100 \%$ & $0 \%$ & $0 \%$ & 5 \\
.33 & $33 \%$ & $67 \%$ & $0 \%$ & 3 \\
.67 & $0 \%$ & $0 \%$ & $100 \%$ & 1 \\
\hline
\end{tabular}


TABLE III

EXPECTANCY TABLES FOR DISFLUENCY TYPES

(continued)

b. Word Repetitions

AGE: 3 year olds and 5 year olds combined

\begin{tabular}{lrrrr}
\hline \hline Mean per 100 words & More & Same & Fewer & Total \\
Not Known & $44 \%$ & $22 \%$ & $44 \%$ & 18 \\
$\leq 1.0$ & $64 \%$ & $18 \%$ & $18 \%$ & 11 \\
$1.01-2.0$ & $14 \%$ & $0 \%$ & $86 \%$ & 7 \\
\hline
\end{tabular}

AGE: 3 year olds

\begin{tabular}{lrrrr}
\hline Mean per 100 words & More & Same & Fewer & Total \\
Not Known & $33 \%$ & $11 \%$ & $56 \%$ & 9 \\
$\leq 1.0$ & $50 \%$ & $25 \%$ & $25 \%$ & 4 \\
$1.01-3.0$ & $20 \%$ & $0 \%$ & $80 \%$ & 5 \\
\hline
\end{tabular}

AGE: 5 year olds

\begin{tabular}{lrrrr}
\hline Mean per 100 words & More & Same & Fewer & Total \\
Not Known & $56 \%$ & $11 \%$ & $33 \%$ & 9 \\
$\leq 1.0$ & $78 \%$ & $14 \%$ & $14 \%$ & 7 \\
$1.01-3.0$ & $0 \%$ & $0 \%$ & $100 \%$ & 2 \\
\hline
\end{tabular}


TABLE III

EXPECTANCY TABLES FOR DISFLUENCY TYPES

(continued)

\section{c. Phrase Repetitions}

AGE: 3 year olds and 5 vear olds combined

\begin{tabular}{lrrrr}
\hline \hline Mean per 100 words & More & Same & Fewer & Total \\
Not Known & $33 \%$ & $33 \%$ & $33 \%$ & 9 \\
$\leq 1.0$ & $50 \%$ & $33 \%$ & $17 \%$ & 12 \\
$1.01-2.33$ & $33 \%$ & $33 \%$ & $33 \%$ & 6 \\
\hline
\end{tabular}

AGE: 3 year olds

\begin{tabular}{lrrrr}
\hline Mean per 100 words & More & Same & Fewer & Total \\
Not Known & $11 \%$ & $56 \%$ & $33 \%$ & 9 \\
$\leq 1.0$ & $25 \%$ & $75 \%$ & $0 \%$ & 4 \\
$1.01-2.33$ & $0 \%$ & $40 \%$ & $60 \%$ & 5 \\
\hline
\end{tabular}

AGE: 5 year olds

\begin{tabular}{lrrrr}
\hline Mean per 100 words & More & Same & Eewer & Total \\
Not Known & $56 \%$ & $11 \%$ & $33 \%$ & 9 \\
$\leq 1.0$ & $62 \%$ & $13 \%$ & $25 \%$ & 8 \\
$1.01-3.0$ & $0 \%$ & $0 \%$ & $100 \%$ & 1 \\
\hline
\end{tabular}


TABLE III

EXPECTANCY TABLES FOR DISFLUENCY TYPES

(continued)

\section{d. Interjections}

AGE: 3 year elds and 5 year olds combined

\begin{tabular}{lccrr}
\hline \hline Mean per 100 words & More & Same & Eewer & Total \\
Not Known & $67 \%$ & $6 \%$ & $28 \%$ & 18 \\
$\leq 1.0$ & $100 \%$ & $0 \%$ & $0 \%$ & 11 \\
$\geq 1.01$ & $25 \%$ & $12 \%$ & $63 \%$ & $8 \%$ \\
\hline
\end{tabular}

AGE: 3 year olds

\begin{tabular}{lcrrr}
\hline Mean per 100 words & More & Same & Fewer & Total \\
Not Known & $89 \%$ & $0 \%$ & $11 \%$ & 9 \\
$\leq 1.0$ & $100 \%$ & $0 \%$ & $0 \%$ & 7 \\
$\geq 1.01$ & $50 \%$ & $0 \%$ & $50 \%$ & 2 \\
\hline
\end{tabular}

AGE: 5 year elds

\begin{tabular}{lcrrr}
\hline Mean per 100 words & More & Same & Fewer & Total \\
Not Known & $44 \%$ & $11 \%$ & $44 \%$ & 9 \\
$\leq 1.0$ & $100 \%$ & $0 \%$ & $0 \%$ & 3 \\
$\geq 1.01$ & $17 \frac{\circ}{0}$ & $17 \%$ & $67 \%$ & 6
\end{tabular}


TABLE III

EXPECTANCY TABLES FOR DISFLUENCY TYPES

(continued)

e. Revision-Incomplete Phrase

AGE: 3 year olds and 5 year olds combined

\begin{tabular}{lrrrr}
\hline \hline Mean per 100 words & More & Same & Fewer & Total \\
Not Known & $50 \%$ & $17 \%$ & $33 \%$ & 18 \\
$\leq 1.0$ & $75 \%$ & $25 \%$ & $0 \%$ & 4 \\
$1.01-2.0$ & $60 \%$ & $20 \%$ & $20 \%$ & 10 \\
$2.01-3.0$ & $0 \%$ & $0 \%$ & $100 \%$ & 4 \\
\hline
\end{tabular}

AGE: 3 year olds

\begin{tabular}{lrrrr}
\hline Mean per 100 words & More & Same & Fewer & Total \\
Not Known & $33 \%$ & $22 \%$ & $44 \%$ & 9 \\
$\leq 1.0$ & $75 \%$ & $25 \%$ & $0 \%$ & 4 \\
$1.01-2.0$ & $0 \%$ & $50 \%$ & $50 \%$ & 2 \\
$2.01-3.0$ & $0 \%$ & $0 \%$ & $100 \%$ & 3 \\
\hline
\end{tabular}

AGE: 5 year olds

\begin{tabular}{lrrrc}
\hline Mean per 100 words & More & Same & Fewer & Total \\
Not Known & $67 \%$ & $11 \%$ & $22 \%$ & 9 \\
$\leq 1.0$ & $0 \%$ & $0 \%$ & $0 \%$ & 0 \\
$1.01-2.0$ & $75 \%$ & $12 \%$ & $12 \%$ & 8 \\
$2.01-3.0$ & $0 \%$ & $0 \%$ & $100 \%$ & 1 \\
\hline
\end{tabular}


TABLE III

EXPECTANCY TABLES FOR DISFLUENCY TYPES

(continued)

f. Dischythmic Phonations

AGE: 3 year elds and 5 year olds combined

\begin{tabular}{lrrrr}
\hline \hline Mean per 100 words & More & Same & Fewer & Total \\
Not Known & $0 \%$ & $67 \%$ & $22 \%$ & 18 \\
0 & $0 \%$ & $100 \%$ & $0 \%$ & 14 \\
.33 & $0 \%$ & $0 \%$ & $100 \%$ & 3 \\
1.67 & $0 \%$ & $0 \%$ & $100 \%$ & 1
\end{tabular}

AGE: 3 year olds

\begin{tabular}{lcccc}
\hline Mean per 100 words & Mere & Same & Fewer & Total \\
Not Known & $0 \%$ & $89 \%$ & $11 \%$ & 9 \\
0 & $0 \%$ & $100 \%$ & $0 \%$ & 8 \\
33 & $0 \%$ & $0 \%$ & $100 \%$ & 1 \\
\hline
\end{tabular}

AGE: 5 vear olds

\begin{tabular}{lcccc}
\hline Mean per 100 words & More & Same & Fewer & Total \\
Not Known & $0 \%$ & $67 \%$ & $33 \%$ & 9 \\
0 & $0 \%$ & $100 \%$ & $0 \%$ & 6 \\
.33 & $0 \%$ & $0 \%$ & $100 \%$ & 2 \\
1.67 & $0 \%$ & $0 \%$ & $100 \%$ & 1 \\
\hline
\end{tabular}


TABLE III

EXPECTANCY TABLES FOR DISFLUENCY TYPES

(cont inued)

g. Tense Pauses

AGE: 3 year olds and 5 year olds combined

\begin{tabular}{lrrrc}
\hline \hline Mean per 100 words & More & Same & Fewer & Total \\
Not Known & $6 \%$ & $78 \%$ & $17 \%$ & 18 \\
0 & $7 \frac{\circ}{8}$ & $93 \frac{8}{8}$ & $0 \%$ & 14 \\
$33-.67$ & $0 \frac{\circ}{6}$ & $25 \%$ & $75 \%$ & 4 \\
\hline
\end{tabular}

AGE: 3 year olds

\begin{tabular}{|c|c|c|c|c|}
\hline Mean per 100 words & More & Same & Fewer & Total \\
\hline Not Known & 0 옹 & $78 \frac{8}{8}$ & $22 \%$ & 9 \\
\hline 0 & $0 \%$ & $100 \%$ & $0 \frac{9}{0}$ & 7 \\
\hline $.33-.67$ & $0 \%$ & $50 \%$ & $50 \frac{2}{8}$ & 2 \\
\hline
\end{tabular}

AGE: 5 year elds

\begin{tabular}{lcccc}
\hline Mean per 100 words & More & Same & Fewer & Total \\
Not Known & $11 \%$ & $78 \%$ & $11 \%$ & 9 \\
0 & $14 \%$ & $86 \%$ & $0 \%$ & 7 \\
$.33-.67$ & $0 \%$ & $50 \%$ & $50 \%$ & 2 \\
\hline
\end{tabular}

TABLE IV

EXPECTANCY TABLES: TOTAL OF ALL DISELUENCIES

AGE: 3 year olds and 5 year olds combined

Mean per 100 words More $\quad$ Same Fewer Total

\begin{tabular}{lllll} 
Not known & $61 \%$ & $0 \%$ & $39 \%$ & 18 \\
\hline
\end{tabular}

AGE: 3 year olds

\begin{tabular}{|c|c|c|c|c|}
\hline Mean per 100 words & More & Same & Fewer & Total \\
\hline Not known & $56 \frac{2}{8}$ & $0 \%$ & $44 \%$ & 9 \\
\hline$\leq 4.0$ & $100 \%$ & $0 \%$ & $0 \%$ & 3 \\
\hline $4.01-6.0$ & $0 \%$ & 0 응 & $100 \%$ & 2 \\
\hline $6.01-8.0$ & $100 \%$ & $0 \%$ & $0 \%$ & 2 \\
\hline$\geq 8.01$ & $0 \%$ & $0 \%$ & $100 \%$ & 2 \\
\hline
\end{tabular}

AGE: 5 year olds

\begin{tabular}{lcccc}
\hline Mean per 100 words & More & Same & Eewer & Total \\
Not Known & $67 \%$ & $0 \%$ & $33 \%$ & 9 \\
$\leq 4.0$ & $100 \%$ & $0 \%$ & $0 \%$ & 2 \\
$4.01-6.0$ & $75 \%$ & $0 \%$ & $0 \%$ & 4 \\
$6.01-8.0$ & $0 \%$ & $0 \%$ & $100 \%$ & 2 \\
\hline
\end{tabular}


collapsed. The coefficient was used to analyze the correlation between the rank order of children according to mean total of disfluencies per 100 words during the first study and the rank order of the present study. The resultant rho of .0862 demonstrates negligible correlation between the initial ranking and current rank order. Table V displays the outcome.

\section{DISCUSSION}

The analysis indicated that the statistical significant differences between the mean 1987 data and that of a year later consisted of five decreases in productions of disfluency types by five different subjects. No significant change was found in production of mean total disfluencies for each child. Negligible correlation was found between initial rank order by mean total disfluencies and rank order a year later. The following discussion will examine: individual changes; expectancy tables; and a comparison of the present study to previous studies.

\section{Individual Changes}

As can be seen in Tables IIa and IIb, two 4 year old subjects and two 6 year old subjects decreased either interjections or disrhythmic phonations at significant levels relative to the rest of their peers. A third 6 year old subject significantly decreased phrase repetitions. It 
TABLE V

SUMMARY OF THE SPEARMAN RANK ORDER COEFFICIENT

RANK ORDER OF THE TOTAL MEAN DISFLUENCIES

PER 100 WORDS FOR 1987 AND 1988

COLLAPSED GROUPS

rho $=.0862$

\begin{tabular}{|c|c|c|c|c|c|}
\hline & Subject & 1987 & Rank & 1988 & Rank \\
\hline & 1 & 1.99 & 1.0 & 7.00 & 11.5 \\
\hline & 2 & 2.32 & 2.0 & 4.99 & 5.0 \\
\hline * & 3 & 2.66 & 3.0 & 6.65 & 8.0 \\
\hline * & 4 & 3.66 & 4.0 & 7.66 & 14.5 \\
\hline \multirow[t]{2}{*}{ * } & 5 & 3.67 & 5.0 & 6.01 & 7.0 \\
\hline & 6 & $4.0 I$ & 6.0 & 8.01 & 16.0 \\
\hline * & 7 & 4.99 & 7.0 & 2.67 & 2.0 \\
\hline \multirow[t]{4}{*}{ * } & 8 & 5.32 & 8.0 & 1.00 & 1.0 \\
\hline & 9 & 5.67 & 9.0 & 7.00 & 11.5 \\
\hline & 10 & 6.00 & 10.5 & 4.32 & 4.0 \\
\hline & 11 & 6.00 & 10.5 & 10.00 & 17.0 \\
\hline \multirow[t]{2}{*}{ * } & 12 & 6.33 & 12.0 & 10.30 & 18.0 \\
\hline & 13 & 6.66 & 13.0 & 6.67 & 9.0 \\
\hline * & 14 & 6.67 & 14.0 & 7.00 & 11.5 \\
\hline * & 15 & 8.33 & 15.0 & 5.99 & 6.0 \\
\hline \multirow[t]{3}{*}{ * } & 16 & 8.34 & 16.0 & 4.00 & 3.0 \\
\hline & 17 & 9.33 & 17.0 & 7.66 & 14.5 \\
\hline & 18 & 12.00 & 18.0 & 7.00 & 11.5 \\
\hline
\end{tabular}

* indicates 3 to 4 year age group

revised totals from the Christiansen (1987) study 
is interesting to note that although significantly fewer productions of a specific disfluency type were produced by the five children, no total disfluency means were decreased by significant amounts. This indicates to this researcher, that other disfluency types produced by those five children were well within normal limits in order to maintain overall normal mean disfluency production. Additionally, significant change was found at both age levels, indicating great variability at both age levels.

At an alpha level of .05, the critical value was .512 . In addition to the five significant changes, five other differences in disfluency types were found to be of marginal significance at a critical value of .5. Of these, tense pauses were decreased marginally by one child in each age group and increased by one 6 year old child. It is interesting to note that both children who decreased tense pause production also significantly decreased one other disfluency, contributing to a total disfluency reduction for each child. However, both total reductions remained within normal limits due to the normal variability of other disfluency types for each child. The marginal increase in tense pauses by one 6 year old was not accompanied by other significant changes. A marginal increase in phrase repetitions produced by a 4 year old was also unaccompanied by other significant changes. As in other cases, mean total disfluency scores did not change significantly for 
these subjects.

The final marginal change was an increase in word repetitions by a 6 year old. It is interesting to note that this child significantly decreased disrythmic phonations while increasing all other types of disfluencies except tense pauses. While tense pause production remained constant, it was maintained at a relatively high level of 67. Again, total change was within normal limits when compared to other children in that age group due to increases in disfluencies by other subjects as well. In fact, two other 6 year olds changed by equal or greater mean totals.

In examining mean changes longitudinally, it seems apparent that a wide variability of change within each disfluency category as well as total mean disfluency scores is the norm rather than the exception. This is consistant with Yairi's (1981, 1982) findings concerning 2 year olds.

When rank order of each child according to mean total disfluencies was analyzed, it was noted that negligible correlation existed between initial rank order and that of a year later. As Table $V$ indicates, only 2 of the eighteen children in the study were within 2 places of their original rank order. One 4 year old child increased from 5 th to 7 th place and a 6 year old decreased from 9 th to 1 th place. The greatest change in rank was from l6th to 3rd place by a 4 year old. One 4 year old and two six year olds 
changed 10 ranks. It is interesting to note that the two groups are distributed throughout the ranking at both times. Initially the 6 year olds were scattered in both extremes in that two of them produced the least disfluencies and two produced the most disfluencies during the 1987 study. However, the 4 year olds had a greater range of total disfluencies during the present study. Three produced the fewest disfluencies and one produced the most disfluencies. These results confirm that variability in disfluency production is common and probably not a function of age nor sampling variability in cross-sectional studies.

Given this variability, expectations of future performance by age alone may be of limited value. The Expectancy Tables were created to assist in clarifying what changes may be predicted if a variety of variables are known.

Expectancy Tables

Previous cross sectional studies have been limited by the fact that they do not address changes within individual children but rather present data derived from different children at different ages. Individual change is assumed to follow the general pattern as determined by mean scores. Normal limits are then determined by standard deviation. The Expectancy Tables in the present study examine actual individual change over time, allowing comparisons of subjects not only according to age, but also according to 
initial mean number of disfluencies per 100 words. Thus, the previous level of disfluency is taken into consideration when determining whether a child increased, decreased, or maintained disfluency levels.

In examining change according to overall, total disfluencies, Table IV indicates that fifty-six percent of the 4 year old subjects increased disfluencies and forty-four percent decreased disfluencies from a year earlier. When specific initial mean number of disfluencies were taken into consideration, as well as age, it can be seen that those children who initially made the fewest disfluencies increased and those who made the most decreased disfluency production. However, according to Table IV those who produced more moderate productions between 4.01 and 6.0 decreased, and those who produced 6.01 and 8.0 increased total disfluency production.

A similiar pattern can be seen for the children at the 6 year age level. Subjects had a slightly greater chance than those of the 4 year age level, of increasing disfluencies at sixty-seven percent and a slightly smaller chance of decreasing disfluencies at thirty-three percent. When total disfluencies were examined in relationship to initial disfluencies, those who initially made the fewest disfluencies (fewer than 4.0) increased and those who made the most (greater than 8.01 ) decreased production. Subjects who initially made between 4.01 and 6.0 disfluencies per 100 
words had a seventy-five percent chance of increasing disfluency and a twenty-five percent chance of decreasing disfluencies. As with the 4 year olds, increased disfluency rate could be expected if initial production was between 6.01 and 8.0 mean disfluencies per 100 words.

This apparent pattern in which the subjects who made the most disfluencies decrease production and those who made the least disfluencies increase production, accompanied by mixed increases and decreases for those whose production is moderate, supports rank order findings in which negligible correlation was found between initial rank order and that of a year later. Again, this indicates that total mean disfluencies per 100 words may not predict disfluency production a year later.

In examining the Expectancy Tables for specific disfluency types, it can be seen that a wide range of variability in change occurred. However, children tended to maintain the same level of production of a few disfluency types. Disrhythmic phonations, tense pauses and phrase repetition productions remained at the same rate for the majority of 4 year olds. Only disrhythmic phonations and tense pause production remained the same for the majority of 6 year olds. As can be seen from the Expectancy Table IIIf all children who changed mean number of disrythmic phonations decreased their production. The rest maintained the same level of production. No 4 year olds produced more 
tense pauses and only fourteen percent (one child) of the 6 year old children who produced no tense pauses initially, increased production. The remainder continued to produce no tense pauses. Half the children who produced tense pauses in both age groups maintained the same level while the remainder decreased mean production. In other words, tense pauses and disrhythmic phonations were produced the most consistently and least frequently by individuals in both age groups.

As noted previously, a small majority of 4 year olds produced the same mean number of phrase repetitions. However, fewer were produced by thirty-three percent and more were produced by eleven percent, indicating individual variability. As can be seen from Table IIIc, seventy-five percent of 4 year old children who initially produced less than 1 phrase repetition per 100 words maintained the same level. Sixty percent of children who produced greater than 1.0 phrase repetition decreased production. Forty percent maintained the same level. Again, variability in change seems to be the rule rather than the exception.

Change in production of other disfluency types at both age levels was highly variable as can be seen in the Expectancy Tables. Generally, the majority of 6 year old children who initially produced the greater mean per 100 of the each remaining disfluncy type tended to decrease production a year later and the majority of those who 
initially produced the lesser mean per 100 words tended to increase production. The four year age group followed this same pattern for revision-incomplete phrases and word repetitions. While interjections were increased by 4 year olds who initially produced the smaller mean number, they were both increased and decreased by those who produced the greater mean per 100 words. Production of part-word repetitions remained the same or increased when the first mean per 100 words was low and remained the same or decreased when the initial means were high.

Generally, it can be seen that variability between individuals is a primary constant that is emerging when examining disfluency types longitudinally. Thus, the longitudinal data supports the cross sectional data in that variability found between cross-sectional studies is also found in the individual variability over time. In addition, it appears that children who initially produced the greatest variability tend to move toward center.

\section{Comparisons}

In comparing the data of the current research with that of previous studies several trends seem to be evolving. There is marked agreement in rank order of repetition disfluency types produced by the 4 year old group. Word repetitions are produced the most frequently and part word repetitions are produced the least frequently in six of the seven sets of data (including the present study). It is 
also interesting to note that revision-incomplete phrases are among the most numerous disfluency types for all studies.

The present study reinforces findings of cross-sectional studies that word repetitions were found to be the most numerous of the repetition types for 6 year olds. However, the current study found part-word repetitions more numerous than phrases repetitions. This disagrees with the cross-sectional data and may be a reflection of the individual variability within this sample. As in the current study, disrhythmic phonations were the least prevalent, and interjections were found to be the most prevalent in all studies. 


\author{
CHAPTER V \\ SUMMARY AND IMPLICATIONS
}

\title{
SUMMARY
}

Investigations into the speech of normal children have indicated that disfluencies are common. It is important for the Speech Language Pathologist to have knowledge of normal disfluencies in children for differential diagnosis, parent counseling, and in order to plan strategies for intervention.

The purpose of this study was to compare the frequency of disfluencies in 4 year old and 6 year old normal male children to the frequency of disfluencies when they were 3 years old and 5 years old respectively. Disfluencies examined included: part-word repetitions, word repetitions, phrase repeptitions, disrhythmic phonations, interjections, revision-incomplete phrases, and tense pauses.

The following questions were addressed:

1. Does the total frequency of occurrence of each disfluency type change significantly over time for each subject?

2. Does the total of all disfluency types combined differ significantly over time for each subject? 
3. How does rank order of individual children compare over time?

One year later, eighteen of the twenty normal male children used in the Christiansen (1987) study were reevaluated in this study. At the time of the current study, nine children ranged in ages from 45 to 53 months $(x=49.5)$, and nine children ranged in ages from 70 to 74 months $(x=72)$. All subjects met specific criterion. Transcripts were made of speech samples and seven disfluency types were identified following the same procedures as in the previous study. Results were analyzed using the Dixon-Massey Test of Outliers, Expectancy Tables were created and changes in rank order were analyzed using the Spearman Rank Order Coefficient.

At a .05 level of significance, the Dixon-Massey Test of Outliers determined that all statistically significant changes in specific disfluency types for individual subjects were decreases in mean production when compared to subjects of the same age group. Two 4 year old children and three 6 year old children each significantly decreased one specific disfluency type. Of the 4 year old children, one decreased interjections and one decreased disrhythmic phonations, as did two 6 year olds. The remaining 6 year old significantly decreased phrase repetitions.

No significant variability was found in mean total disfluencies per 100 words when each child was compared to 
others in his age group according to analysis at a .05 level of significance. The variability among individuals ranged from a decrease of 4.34 disfluencies to an increase of 4.0 disfluencies per 100 words during the 3 to 4 year time span and from a decrease of 4.99 disfluencies to an increase of 5.01 disfluencies per 100 words during the 5 to 6 year time span.

Negligible correlation at a rho of .0862, was found between initial ranking and current rank order utilizing the Spearman Rank Order Coefficient.

Expectancy Tables were created from the data to assist in predicting future disfluency when baseline information is known for specific disfluency types and total mean disfluencies per 100 words.

Results indicate that 4 year olds produced disfluency types in the following descending order: interjections, word repetitions, revision-incomplete phrases, phrase repetitions, part-word repetitions, tense pauses and disrhythmic phonations. The descending order of frequency of occurence for 6 year olds was: interjections, revision-incomplete phrases, word repetitions, part-word repetitions, phrase repetitions, tense pauses, and disrhythmic phonations. These findings are consistent with previous studies indicating that interjections, word repetitions, and revision-incomplete phrases are prevalent disfluency types and disrhythmic phonations are among the 
least common disfluency types in normal 4 and 6 year old children. This indicates that a prevalance of disrhythmic phonations may be an indicator of abnormal disfluency.

\section{IMPLICATIONS}

Clinical

The longitudinal data presented in this study contributes uniquely to the Speech Language Pathologists knowlege of normal disfluencies in 3 to 4 year old children and 5 to 6 year old children in that it presents disfluency as a dynamic process in which each individual child varies over time in relationship to his peers. This normal process of change for each child includes: (l) the tendency toward variability in production of individual disfluency types; (2) the tendency toward variation in total disfluency production over time; (3) children at 3 and 5 years of age who exhibit the least disfluencies initially tend to increase disfluencies and those who exhibit the most disfluencies will probably decrease disfluencies. This knowledge will assist the Speech Language Pathologist in viewing disfluency as variable over time for each individual child and in counseling parents as to the dynamic aspect of normal disfluency. Knowledge that the prevalence of disrhythmic phonations appears to be an indicator of abnormal disfluency can assist the Speech Language 
Pathologist in the differential diagnosis of stuttering.

\section{$\underline{\text { Research }}$}

Replication of the present research could contribute to normative data of disfluencies. The current study can be viewed as laying the groundwork for research involving a greater number of subjects. The resultant data could be generalized to the greater population. In this way, Expectancy Tables could assist in predicting future disfluency behavior.

More longitudinal studies will contribute to the knowledge of the dynamic aspect of individual disfluency development. Only Yairi's (1982) one year study of two year olds has viewed disfluencies longitudinally. Following the same subjects in the present study could reveal individual patterns of disfluencies over a greater length of time.

The relationship between language abilities and disfluencies could add insight as to the nature of stuttering. For example, the relationship between the production of specific disfluency types, such as, revision-incomplete phrases or interjections, to the development of metalinguistic awareness could assist in understanding the prevalance of this type of disfluency.

Individual variability within the current findings support Yairi's conclusion in his 1982 longitudinal study that disfluency development does not seem to follow a "one-way developmental course." Continued investigation 
into individual variability in disfluency production is necessary to further the speech Language Pathologist's understanding of normal disfluency in children. 
REFERENCES

Adams, M. (1977). A clinical strategy for differentiating the normally nonfluent child and the incipient

stutterer. Journal of Fluency Disorders, 2, 141-148.

Arnold-Cockburn, S. (1987). Discontinuities in normal 30 to 36 month old and 54 to 60 month old female children. Masters Thesis. Portland State University.

Bloodstein, O. (1960). The development of stuttering. Journal of Speech and Hearing Disorders, 25, 366-376.

Bloodstein, O., and Grossman, M. (1981). Early stutterings: some aspects of their form and distribution. Journal of Speech and Hearing Research, 298-302.

Branscom, H., Hughes, J., and Oxtoby, E.T. (1955). Studies of non-fluency in speech of preschool children. In $W$. Johnson (ed.), stuttering in children and adults.

Minnesota: University of Minnesota Press.

Christiansen, P. (1987). Disfluencies in normal three year old and five year old male children. Masters Thesis. Portland State University.

Davis, D. (1939). The relation of repetitions in the speech of young children to certain measures of language maturity and situational factors. Journal of Speech Disorders, $4,303-318$.

DeJoy, D., and Gregory, H. (1985). The relationship between age and frequency of disfluency in preschool children. Journal of Eluency Disorders, 10, 107-122.

Dixon, W., and Massey, F. (1957). Introduction to statistical analysis. New York: McGraw-Hill Book Co., Inc.

Egland, G. (1955). Repetitions and prolongations in the speech of stuttering and nonstuttering children. In $W$. Johnson (ed.), stuttering in children and adults. Minneapolis: University of Minnesota Press. 
Emerick, L., and Hatten, J. (1979). Diagnosis and evaluation in speech pathology. Englewood Cliff, NJ: PrenticeHall, Inc.

Floyd, S., and Perkins, w. (1974). Early syllable dysfluency in stutterers and nonstutterers: A preliminary report. Journal of Communication Disorders, 7, 279-282.

Haynes, W., and Hood, S. (1977). Language and disfluency variables in normal speaking children from discrete chronological age groups. Journal of Fluency Disorders, $2,57-74$.

Herrick, S. (1987). Repetitions in the speech of normal two year old males. Masters Thesis. Portland State University.

Johnson, w. (1961). Measurements of oral reading and speaking rate and disfluency of adult male and female stutterers and nonstutterers. Journal of Speech and Hearing Disorders, 7, 1-20.

Johnson, W., Brown, Curtis, Edney, and Klaster. (1959). The enset of stuttering. Minneapolis: University of Minnesota Press.

Kools, J., and Berryman, J. (1971). Differences in disfluency behavior between male and female nonstuttering children. Journal of Speech and Hearing Research, 14, 125-130.

Riley, G. (1972). A stuttering severity instrument for children and adults. Journal of Speech and Hearing Disorders, 37, 314-320.

Semler, C. (1987). The differential role of the SSI with normal pre-school children. Masters Thesis. Portland State University.

Shine, R. (1980). Direct management of the beginning stutterer. Seminars in Speech, Language, and Hearing, 1 , 339-350.

Silverman, E. (1972). Generality of disfluency data collected from preschoolers. Journal of Speech and Hearing Research, 15, 84-92.

Starkweather, C. (1985). Development of fluency in normal children. In Stuttering therapy. Memphis, Tennessee: Speech Foundation of America. 
Van Riper, C. (1971). The nature of stuttering. Englewood Cliffs, New Jersey: Prentice-Hall.

Wexler, K. (1982). Developmental disfluency in 2, 4, and 6 year old boys in neutral and stress situations. Journal of Speech and Hearing Research, 25, 229-234.

Wexler, K., and Mysak, E. (1982). Disfluency characteristics and 2,4 , and 6 year old males. Journal of Eluency Disorders, 7, 37-46.

Williams, D., Silverman, F., and Kools, J. (1968). Disfluency behavior of elementary school stutterers and nonstutterers: The adaptation effect. Journal of Speech and Hearing Research, 11, 622-630.

Wingate, M. (1964). A standard definition of stuttering. Journal of Speech and Hearing Disorders, 29, 484-489.

Winkler, L., and Ramin, P. (1986). Temporal characteristics in the fluent speech of child stutterers and nonstutterers. Journal of Fluency Disorders, 11, 217229 .

Yairi, E. (1981). Disfluencies of normally speaking twoyear-old children. Journal of Speech and Hearing Research, 490-495.

Yairi, E. (1982). Longitudinal studies of disfluencies in two-year-old children. Journal of Speech and Hearing Research, 25, 155-160.

Yairi, E., and Clifton, N. (1972). Disfluent speech behavior of preschool children, high school seniors, and geriatric persons. Journal of Speech and Hearing Research, 15, 714-719.

Yairi, E., and Lewis, B. (1984). Disfluencies at the onset of stuttering. Journal of Speech and Hearing Research, $27,145-154$. 
APPENDIX A

CONSENT FORM 
CHILD'S NAME : NICKNAME :

BIRTHDATE: AGE :

1. Since participating in this study in 1987 has your child been diagrosed as demonstrating any of the following:

$\begin{array}{lll}\text { developmental delay } & \text { yes } & \text { no } \\ \text { neurological impairment } & \text { yes_ no } & \text { no } \\ \text { hearing loss } & \text { yes } & \text { yes_ no } \\ \text { mental retardation } & \text { no_- } \\ \text { orthopedic or physical handicap yes_ }\end{array}$

2. Has your child received speech therapy for stuttering? yes no

I hereby give my permission for my child,

to participate in this study. My child may attend a video taping session at an agreed upon date and time.

I understand I may withdraw my permission at any time during this study without penalty. 
APPENDIX B

LETTER OF INTRODUCTION 


\section{LETTER OF INTRODUCTION}

\section{COLLECE OF \\ LBERRL ARTS ANO SCIENCES}

DEPARTMENT OF

SPEECH COMMUNICATION

SPEECH AND

HEARING SCIENCES

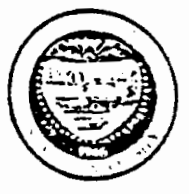

PORTLANOO

STATE

UNIVERSITY

T.O. BOX>51

PORTLAND. ORTCION

97207

$503 / 229.353$

Pamela Paguia Christianson

P.O. Box 647

Barrow, Alaska. 99723

October 21, 1937

Dear

I wanted to thark you personally for permitting your son's participation in my thesis study. I am Einally done!

Results of my study indicated that the Eive-year-olo male children used more intezjections. (such.as, "um", "you know" \&:" "well") in their speech than the three-vear-old male children. In addition,. the thzes-year-old male chiloren tend to use more repetitions in their speech than the five-yeaz-old male children. Isn't it exciting?! We (the gIaduate students in the speech and heazing program) are gathering more information about the speech behaviors of presciool children.

Well, there is another graduate student who also feels that this study would.be interesting. However, she would like to look. at the speech behaviors of the same children but at the foux-year-old and six-year-old age levels. Ihis study would give us:more information on how the speech behaviors of chilaren change over time. I mentioned that you were interested in coming back to continue the study. You will be hearing from the interested grabuaterstuoent. within tine rext few montins.

I thank you for your continued cooperation.

Oh, yes'my last name has cingned as I got married in Hawaii on August 8, 1987 anc yes, I am now living in an Eskimo viliage calied Pt. JazIow. Elease enjoy tine sun and warmer weather in oregon for me.

sincerely, 
APPENDIX C

FOLLOW UP LETTER 
Portland State Lniversir:

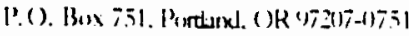

March 21, 1988

Dear

I am a graduate student at portland State University in the Department of Speech Communication, and I am conducting a study about how often preschool children repeat sounds and phrases and stop the flow of air during speech. Your child participated in similiar study last year and was found to have normal speech. I am collecting more information to determine how the same children's speech has changed as they have grown older.

I would like to video tape your child during 15 minutes of play and conversation with me. This would be done at Portland State University at a time that is good for both you and our department. In addition to the taped conversation, your child will receive a free hearing screening test.

Your child's name will not be used in reporting the results and the video tapes will only be available to authorized University personnel. You may withdraw your child from this study at any time without penalty.

If you are willing to participate in tinis study, please complete the attached form and return it to me as soon as possible in the envelope provided. After I receive this form, I will call you to schedule a taping session. Please call me if your have any questions at the portland State University communications office: 464-3533, or at my home, 639-1439. I greatly appreciate your cooperation.

If you have any questions as a result of your participation in this study, please contact the secretary for the Human Subjects Review Committee, the Ofice of Grants and Contracts, 303 Cramer Hall, Portland State University, P.o. Box 751, Portland, Oregon, 97207, 464-3417.

\section{Sincerely,}

Mary B. Cox

Graduate Student

Speech and Hearing Sciences 
APPENDIX D

LIST OF STIMULI 


\section{LIST OF STIMULI}

TOYS:

1 Telephone

1 Wind-up toy

2 Cars

2 Dolls

2 Medium-size rubber toys

3 Puppets

Fischer Price Play House

Fischer Price Farm Set

Tea and Plate set

\section{QUESTIONS :}

Who lives at your house?

Tell me about them.

What is your bedroom like?

Do you have any pets?

Tell me about them.

What do you do to take care of a pet?

What do you do at school?

Tell me about your friends.

What did you do for your last birthday?

Tell me about your favorite TV show.

Tell me how to make a peanut butter and jelly sandwich.

\section{PROMPTS:}

Tell me more.

What else?

Why?

Mmm. Hmmm.

Tell me about it.

oh, wow.

Pretend you are...

I wonder if... 


\section{APPENDIX E}

RULES FOR CALCULATING 300 WORD SAMPLES 


\section{RULES FOR CALCULATING 300 WORD SAMPLES}

1. Contractions of a noun or pronoun and a verb, such as "I'm" and "they're" are counted as one word. Contractions of a verb form and "not", as in "won't" and "can't" are also counted as one word. (Branscom et al., I955).

2. Hyphenated words occurring together are scored as one word, as in "teeter-totter" (Branscom et al., 1955).

3. Nonsense syllables are not counted as words.

4. Interjections, such as "uh" and "um," and extraneous words such as "well" and "you know" are not included in the total word count.

5. The last complete form is included in the total word count for each instance of repetition. "What-what-what' or "wh-wh-what" are each counted as one repetition: "What can I, what can I" is counted as three words.

6. All words are included in the total count for each instance of revision-incomplete phrase. Part-words are 
7. Solitary affirmative and negative responses, such as "yes," "yeah," "no" are omitted form the total word count to prevent inflating the speech sample. However, when they are. followed immediately by another word or phrase, they are counted. (Yairi and Lewis, 1984).

8. The rising or falling terminal intonation contour determines utterance segmentation.

9. The total word count excludes words that initiate two uttterances or more in succession and which are not associated with meaningful text. For example: "and" and "oh."

10. Words representing animal noises are included in the total word wound only when used in phrases, such as "the cat says "meow." The word, "meow," would not be counted when produced in isolation. 


\section{APPENDIX F}

RULES FOR IDENTIFYING DISFLUENCIES 


\section{RULES FOR IDENTIFYING DISFLUENCIES}

1. Repetitions are cancelled when any nonidentical comment is inserted between identical remarks. Included are words such as: "yes," "no," and personal names. Examples: "Take it away, no, take it away," or "See me. Look. See me."

2. Repetition of a total phrase comprises a phrase repetition. Example: "Who are they? Who are they?"

3. The repetition of a name several times is not considered a repetition. Example: "Billy, Billy, Billy."

4. Interjections between repetitions or revision-incomplete phrases does not negate the disfluency. A neutral vowel is scored as an interjection. Examples: "what do, uh, what do you want?" and "Where do, uh, what do you want?"

5. One syllable word repetitions are counted as word repetitions, rather than syllable repetitions. Example: "I."

6. Part-word repetitions include repetitions which are part of a contraction. Example: "I-I-I'm." 
7. Imitations of continuous sounds, such as motor noises, are not counted as repetitions.

8. Quotations entailing repetitions are not counted as repetitions. Example: "Mary had a little lamb, little lamb, little lamb."

9. A change of thought or word are counted as revision-incomplete phrases even though they may include repeated words. Example: "I come to the-I came to the house."

10. Repetitions of meaningful or nonsensical syllables, words, or phrases for the apparent enjoyment of rhythm and not counted as repetitions using context as the deciding factor.

11. Words repeated for emphasis are not scored as repetitions. Example: "Cold, cold water."

12. Interjections include extraneous sounds or words which are not part of the phrase or sentence and are unintentionally produced. Regardless of the number of times an interjection is produced within one instance, it is counted as only one interjection. Examples: "I uh-uh like 
that one" is counted as one interjection; "I uh-uh like that uh one" is counted as two interjections.

13. If the content or grammar of a phrase is changed or pronunciation of a word is modified it is counted as a revision-incomplete phrase. Example: He wa-he went there;" "He-she ran fast."

14. Disrhythmic phonations include audible or silent continuations of a sound or articulatory posture which interrupts the rhythmic flow of speech. Sound prolongations, broken words, and hard attacks are all disrhythmic phonations.

15. Tense pauses are comprised of tension between words, part-words, and interjections. 
APPENDIX G

CODING DISELUENCIES 
CODING DISFIUENCIES

Part-word Repetition

$(\mathrm{PW})$

Word Repetition

(WR)

Phrase Repetition

( PHR)

Interjection

( I )

Revision-Incomplete Phrase

(RIP)

Disrhythmic Phonation

( DP )

Tense Pause

( TP ) 


\section{APPENDIX H}

INSTRUCTIONS FOR SELECTION OF CONTENT TRANSCRIPTS

FOR RELIABILITY TESTING 


\section{INSTRUCIIONS FOR SELECTION OF \\ CONTENT TRANSCRIPTS FOR RELIABILITY TESTING}

Parallel play situations involving a child and an adult have been videotaped and the children's conversations have been transcribed verbatim. You are to choose five transcripts using a random order table. Then you are to extract ten episodes from each of five transcripts and form a content transcript for each one. Only basic information is to be included with no additional words. The following disfluencies are to be omitted: part-word repetitions ( $P W$ ), word repetitions (W), phrase repetitions (PHR), interjections (I), revision-incomplete phrases (RIP), disrhythmic phonations (DP) and tense pauses (TP).

Use the following guidelines when creating the content transcript:

1. Episodes ten through ninteen should be extracted from each of five transcripts to form the content transcriptions.

2. Only use words present in the transcripts.

3. If the episodes are very short and are free of disfluencies, include the full episode presented in the original transcriptions. Examples of short episodes to be included as is: "maybe", "hi", "just go away". 
4. Omit the single word utterances, "yes", "yeah", "no" if not immediately followed by other words.

5. Omit the following disfluencies: part-word repetitions, word repetitions, phrase repetitions, interjections, revision-incomplete phrases, disrhythmic phonations, tense pauses. Examples: "Let's go-Let's go home" would be written as "Let's go home"; "Um see the um dog" would be written as "See the dog".

6. Only include the most complete form when transcribing revision-incomplete phrases. Example: "He likes-she likes it" would be written "She like it".

7. Label an unintelligible episode as unintelligible. If only part of the episode is unintelligible, label that part unintelligible but include the understandable section in its complete form.

8. Do not included additional sounds in the content transcript.

Examples of Full Transcription and Corresponding Content: Full Transcription Content Transcription

1. I sit here?

2. That, um, that there.

3. I-I-I like it unintelligible. 3. I like it unintelligible.

4. Lo-Look at this-at that one. 4. Look at that one. 5. It-it's a car. 5. It's a car. 


\section{APPENDIX I}

INSTRUCTIONS TO RELIABILITY JUDGES 


\section{INSTRUCTIONS TO RELIABILITY JUDGES}

\section{Purpose}

The purpose of this reliability testing is to determine the investigator's accuracy in identifying part-word repetitions, word repetitions, phrase repetitions, interjections, revision-incomplete phrases, disrhythmic phonations, and tense pauses.

\section{General Instructions}

You will be given five partially complete transcripts which have been randomly chosen from a group of 49 month old children and a group of 72 month old children. Each transcript contains only the content of ten episodes. All disfluencies are omitted. Transcripts may not be perfect in that mistakes can be made even in determining the content of the episodes. After listening to the entire videotaped episode, determine if you agree with all the words in the transcript that have been given to you. Add other words you are hearing along with all disfluencies. Episodes may be reviewed when requested. No talking or discussion may occur during reliability testing.

Operational definitions of disfluencies are as follows:

1. Part-Word Repetitions: unintentional repetitions of parts of words, either syllable or sound. Only one 
repetition instance is credited although a sound or syllable may be repeated several times. An interjection between repeated sounds or syllables does not negate the repetition.

Examples: $\mathrm{b}-\mathrm{b}-\mathrm{bal} \mathbf{l}$

$$
\begin{aligned}
& \text { nobo-nobody } \\
& \text { down-um-downtown }
\end{aligned}
$$

2. Word Repetitions: the unintentional repetition of either single syllable or multiple syllable whole words. An interjection between word units does not negate the repetition. Only one repetition is credited even though a word is repeated several times. Examples: one-one-one more candy can-um-can-um-can I go now

3. Phrase Repetitions: the unintentional repetition of two or more words or part of a word. An interjection between phrase units does not negate the repetition. Examples: and can, um, and can I go? he was $\mathrm{g}^{-}$, he was going.

4. Interjections: extraneous sounds such as "um," "er," "hm", or words such as "well" and "you know" which are inserted within the flow of speech and are not part of the phrase or sentence. Only one interjection is credited per interjection event, even though it may be repeated several times.

Examples: "um-um, can I go to the store?" contains only one instance of interjection. 
"Uh, I went to the park and um-um, we saw some dogs" contains two interjection instances.

"Let's put it, you know, over there" contains one interjection instance.

5. Revision-Incomplete Phrases: Instances in which: the content of a phrase is modified; there is a grammatical modification; there is a change in the pronounciation of a word. An interjection between a revision-incomplete phrase does not negate the disfluency. Also known as a false start.

Examples: you g-you can go to the store my dog-there's the other car they come-came to my house

6. Disrhythmic Phonations: an interruption of the rhythmic flow of speech through the audible or silent continuation of a sound or articulatory posture of excessive duration. Occurs within words and includes broken words and prolongations. Examples: "dri-i-ve the car", "b---ut"

7. Tense Pauses: barely audible manifestations of heavy breathing or muscular tightening between words, and part-words. Occurrence within a word would classify this phenomena as a disrhythmic phonation. Examples: "can we go to the zoo?"

"I am going to the store?" 
Disfluencies should be identified as follows:

PW: part-word repetition

WR: word repetition

PHR: phrase repetition

I: interjection

RIP: revision-incomplete phrase

DP: disrhythmic phonation

TP: tense pause 